Atmos. Chem. Phys., 18, 13393-13410, 2018

https://doi.org/10.5194/acp-18-13393-2018

(c) Author(s) 2018. This work is distributed under

the Creative Commons Attribution 4.0 License.

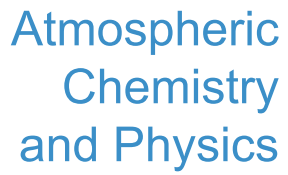

Evu

\title{
An empirical model of nitric oxide in the upper mesosphere and lower thermosphere based on 12 years of Odin SMR measurements
}

\author{
Joonas Kiviranta, Kristell Pérot, Patrick Eriksson, and Donal Murtagh \\ Chalmers University of Technology, Department of Space, Earth and Environment, 412 96, Gothenburg, Sweden \\ Correspondence: Kristell Pérot (kristell.perot@ chalmers.se)
}

Received: 15 January 2018 - Discussion started: 2 February 2018

Revised: 10 August 2018 - Accepted: 20 August 2018 - Published: 20 September 2018

\begin{abstract}
Nitric oxide (NO) is produced by solar photolysis and auroral activity in the upper mesosphere and lower thermosphere region and can, via transport processes, eventually impact the ozone layer in the stratosphere. This work uses measurements of NO taken between 2004 and 2016 by the Odin sub-millimeter radiometer (SMR) to build an empirical model that links the prevailing solar and auroral conditions with the measured number density of NO. The measurement data are averaged daily and sorted into altitude and magnetic latitude bins. For each bin, a multivariate linear fit with five inputs, the planetary $\mathrm{K}$ index, solar declination, and the F10.7 $\mathrm{cm}$ flux, as well as two newly devised indices that take the planetary $\mathrm{K}$ index and the solar declination as inputs in order to take NO created on previous days into account, constitutes the link between environmental conditions and measured NO. This results in a new empirical model, SANOMA, which only requires the three indices to estimate $\mathrm{NO}$ between 85 and $115 \mathrm{~km}$ and between $80^{\circ} \mathrm{S}$ and $80^{\circ} \mathrm{N}$ in magnetic latitude. Furthermore, this work compares the NO calculated with SANOMA and an older model, NOEM, with measurements of the original SMR dataset, as well as measurements from four other instruments: ACE, MIPAS, SCIAMACHY, and SOFIE. The results suggest that SANOMA can capture roughly $31 \%-70 \%$ of the variance of the measured datasets near the magnetic poles, and between $16 \%$ and $73 \%$ near the magnetic equator. The corresponding values for NOEM are $12 \%-38 \%$ and $7 \%-40 \%$, indicating that SANOMA captures more of the variance of the measured datasets than NOEM. The simulated NO for these regions was on average $20 \%$ larger for SANOMA, and $78 \%$ larger for NOEM, than the measured NO. Two main reasons for SANOMA outperforming NOEM are identified. Firstly, the input data (Odin SMR NO) for SANOMA span over 12 years, while the input
\end{abstract}

data for NOEM from the Student Nitric Oxide Experiment (SNOE) only cover 1998-2000. Additionally, some of the improvement can be accredited to the introduction of the two new indices, since they include information of auroral activity on prior days that can significantly enhance the number density of NO in the MLT during winter in the absence of sunlight. As a next step, SANOMA could be used as input in chemical models, as a priori information for the retrieval of NO from measurements, or as a tool to compare Odin SMR NO with other instruments. SANOMA and accompanying scripts are available on http://odin.rss.chalmers.se (last access: 15 September 2018).

\section{Introduction}

Nitric oxide (NO) is a reactive free radical and, together with Nitrogen dioxide $\left(\mathrm{NO}_{2}\right)$, constitutes the $\mathrm{NO}_{x}$ compounds. Whereas tropospheric $\mathrm{NO}_{x}$ may originate from both natural sources, such as forest fires, and anthropogenic sources, such as combustion engines (Wallace and Hobbs, 2006), NO in the mesosphere and lower thermosphere (MLT, $\sim 50$ $150 \mathrm{~km}$ ) has a purely natural origin. Knowledge about NO in this region is of great importance, because it can affect the atmospheric layers below. To understand how, we need basic knowledge on the chemical reactions that create and destroy NO. In the MLT, NO can be produced by two mechanisms: either direct radiation from the sun in the form of solar soft X-rays $(8 \leq \lambda \leq 12 \AA)$ or energetic particle precipitation (EPP) (Barth et al., 1999; Sinnhuber et al., 2012). These particles can include electrons, protons, or heavier ions. These may originate directly from the sun, from aurorae and the ra- 
diation belts during geomagnetic storms, or from outside of the solar system.

Previous studies have established that EPP from auroral activity dominates the variation of NO near the magnetic poles, while solar soft X-rays contribute more near the magnetic equator (Gérard and Barth, 1977; Barth et al., 1999; Sinnhuber et al., 2012). NO in the MLT is created through the reaction between molecular oxygen and an excited nitrogen according to the equation

$\mathrm{N}\left({ }^{2} \mathrm{D}\right)+\mathrm{O}_{2} \rightarrow \mathrm{NO}+\mathrm{O}$,

in which $\mathrm{N}\left({ }^{2} \mathrm{D}\right)$ denotes an excited nitrogen atom. Excited nitrogen is created by the two reactions

$\mathrm{N}_{2}+e^{*} \rightarrow \mathrm{N}\left({ }^{2} \mathrm{D}\right)+\mathrm{N}$,

and

$\mathrm{NO}^{+}+e \rightarrow \mathrm{N}\left({ }^{2} \mathrm{D}\right)+\mathrm{O}$

in which $e^{*}$ indicates an energetic electron, originating from either EPP or solar soft X-rays (Marsh et al., 2004). This implies that auroral or solar activity is necessary to form NO in the presence of an oxygen molecule. However, solar light destroys NO in the cannibalistic reaction

$\mathrm{NO}+h v \rightarrow \mathrm{N}+\mathrm{O}$,

$\mathrm{N}+\mathrm{NO} \rightarrow \mathrm{N}_{2}+\mathrm{O}$.

Therefore the amount of NO is affected by seasonal variation of sunlight. Under sunlight conditions in the MLT region, NO has a chemical lifetime of less than 1 day, whereas during the polar night in winter, it may persist for several weeks (Minschwaner and Siskind, 1993). This increased lifetime, together with a stable polar vortex, can eventually result in the descent of $\mathrm{NO}_{x}$ into the stratosphere where it can partake in catalytic cycles to destroy ozone (Siskind et al., 2000; Pérot et al., 2014). Additionally, the amount of NO influences the thermal balance of the MLT via infrared cooling (Richards et al., 1982). These effects highlight the importance of understanding the mechanisms by which solar and auroral activity create and destroy NO.

This study focuses on the effect of solar and auroral activity on the amount of NO in the MLT. Over the past several decades, at least six satellites have measured NO in the MLT region. These include the past instruments, SNOE (Student Nitric Oxide Experiment), SCIAMACHY (Scanning Imaging Absorption spectroMeter for Atmospheric CHartographY), and MIPAS (Michelson Interferometer for Passive Atmospheric Sounding), as well as the currently active Odin SMR (sub-millimeter radiometer), SOFIE (Solar Occultation for Ice Experiment), and ACE (Atmospheric Chemistry Experiment) instruments. The limitation of satellite measurements is that they only cover certain locations and periods of time. Yet, many applications, such as chemical models of the upper atmosphere, require information on the amount of $\mathrm{NO}$ at any given time or location. To help bridge this gap, a model that connects known environmental conditions, such as auroral activity, with measured NO can help to provide an estimate of NO at any time and place. Such a model can also help validate and constrain poorly resolved or underdetermined parameters of first principle models.

Marsh et al. (2004) derived an empirical model, NOEM (Nitric Oxide Empirical Model), which calculates the zonally averaged number density of NO on a grid of magnetic latitude and altitude using the $\mathrm{Kp}$ index, solar declination, and the $10.7 \mathrm{~cm}$ solar flux as inputs. Section 2.3 describes the $\mathrm{Kp}$ index and $10.7 \mathrm{~cm}$ solar flux while Sect. 4 specifies the parameters of NOEM in more detail. Empirical orthogonal function (EOF) analysis of NO measured with SNOE, which operated between 1998 and 2000 and measured UV-fluorescence scattering of incident solar radiation (Barth et al., 2003), forms the basis for the derivation of NOEM. Bender et al. (2015) and Bermejo-Pantaleon et al. (2011) use the NO calculated with NOEM as a priori dataset in the NO retrievals of the SCIAMACHY and MIPAS instruments respectively. Moreover, NOEM constitutes the upper boundary for the NCAR (National Center for Atmospheric Research) WACCM (Whole Atmosphere Community Climate Model) at $140 \mathrm{~km}$ and helps to evaluate the response of WACCM to variability at around $100 \mathrm{~km}$ in altitude.

However, no study has validated NOEM or proposed a contending model since its release. This study aims to fill these two gaps by building a new empirical model based on NO measurements in the MLT by Odin SMR for the period 2004-2016. We hypothesize that an empirical model derived from Odin SMR should be more accurate than NOEM because the Odin SMR measurements include a larger range of solar conditions over a period of over 12 years. Furthermore, SNOE measured only daytime NO whereas SMR provides NO measurements during both daytime and nighttime. This might introduce some discrepancy between NOEM and the resulting empirical model, since the concentration of NO is characterized by a strong diurnal variation, depending on latitude and altitude (Bermejo-Pantaleon et al., 2011).

This study primarily aims to derive a new empirical model based on the 12 years of Odin SMR measurements to calculate NO in the MLT. This new model will be named the SMR Acquired Nitric Oxide Model Atmosphere (SANOMA). Additionally, this study aims to evaluate the performance of both SANOMA and NOEM by comparing simulated NO with measurements from the independent NO-measuring instruments SOFIE, SCIAMACHY, ACE, and MIPAS.

Section 2 describes the SMR NO dataset as well as geomagnetic and solar indices, while Sect. 3 thoroughly describes the method used to derive SANOMA from the Odin SMR observations. Finally, Sect. 4 assesses the performance of both NOEM and SANOMA by comparing their simulated NO with measured NO from aforementioned satellites, followed by a discussion in Sect. 5 . 


\section{Data description}

This section outlines the Odin SMR dataset that forms the basis for SANOMA. Section 2.1 describes the contents of the original dataset of Odin SMR measurements while Sect. 2.2 presents the steps taken from this dataset to the NO data used for the analysis. Finally, Sect. 2.3 offers an overview of the indices used in this study to describe auroral and solar activity.

\subsection{Odin SMR}

The Odin SMR instrument scans the limb of the atmosphere and has been observing NO thermal emission lines in a band centered around $551.7 \mathrm{GHz}$ since October 2003 (Sheese et al., 2013). Frisk et al. (2003) provide a description of the Odin SMR instrument. Odin orbits the Earth in a sun-synchronous orbit with ascending and descending nodes around 06:00 and 18:00 LT, respectively (Murtagh et al., 2002), and provides near-global coverage between approximately $82^{\circ} \mathrm{S}$ and $82^{\circ} \mathrm{N}$, although some measurements can be located at higher latitudes, as the satellite is turned to point towards the poles when conditions allow for this. From 2003 to 2007, the Odin SMR instrument split its measurement time between aeronomy and astronomy modes. Consequently, during this period the NO mode of the SMR instrument operated over a $24 \mathrm{~h}$ period approximately once per month, whereas since 2007 it has measured approximately four $24 \mathrm{~h}$ periods each month. Since the SMR instrument measures microwave emission, the dataset also contains both day- and nighttime measurements.

Using the measured emission spectra, an inversion algorithm derives the volume mixing ratio (VMR) of $\mathrm{NO}$ as a function of altitude for the location of the measurement with an altitude resolution of $\sim 4 \mathrm{~km}$. This inversion technique uses the measured brightness temperatures of the NO emission from the various tangent altitudes of a single limb scan as well as a priori NO climatology to ascertain an estimate for the VMR of NO as a function of altitude. Version 3.0 Level 2 NO VMR constitutes the Odin SMR data used in this study.

Only measurements in which the measurement response, a measure of the relative contributions of the measurement and the a priori dataset, exceeds 0.75 are considered for our analysis. Although no study has validated the version 3.0 Level 2 data, Bender et al. (2015) found that version 2.1 SMR NO measurements were consistent with $\mathrm{NO}$ measurements from the ACE, MIPAS, and SCIAMACHY instruments.

\subsection{Daily zonal averages}

SANOMA will express NO in number density to facilitate its comparison to NOEM. The Odin SMR measured VMR at each altitude is converted to number density (molecules $\mathrm{cm}^{-3}$ ) with the ideal gas law in which the pressure and temperature originate from an a priori background

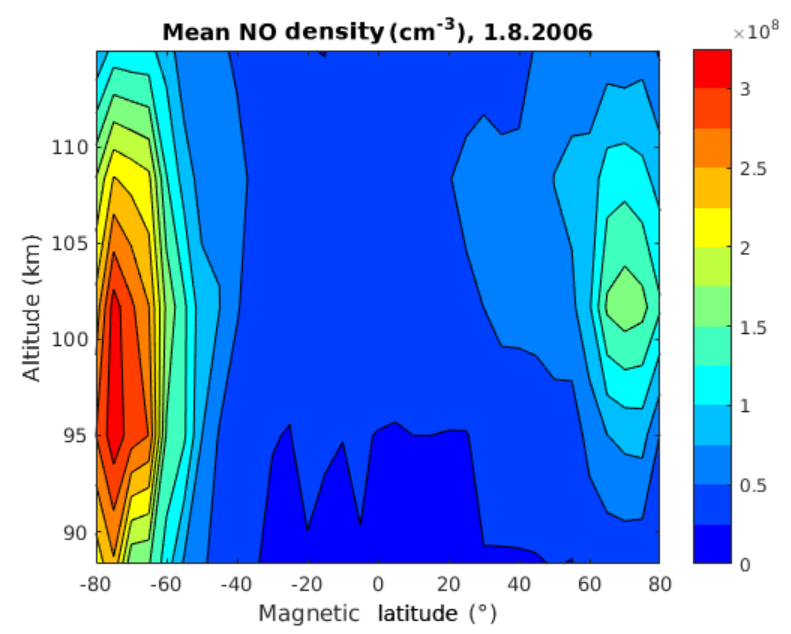

Figure 1. Mean NO density in molecules per cubic centimeter for 1 August 2006 calculated from V3.0 Level 2 Odin SMR data.

atmosphere. For the analysis, an algorithm calculates the daily averages of NO number density as a function of altitude and altitude-corrected magnetic latitude. Since the original dataset contains measurements on geographical coordinates, a MATLAB routine based on the IGRF-12 (International Geomagnetic Reference Field) internal field model, converts the geographical latitude to altitude-corrected magnetic latitude (Thebault et al., 2015), denoted with $\Lambda$.

For each measurement day, the NO number density is sorted into bins according to altitude and magnetic latitude. Prior to sorting, each individual measurement is interpolated in altitude with grid points at the centers of the altitude bins. The bins for altitude run from 85 to $\sim 118.33 \mathrm{~km}$ with a bin width of $\sim 6.67 \mathrm{~km}$. This altitude range reflects the area in which the measurement response of the SMR-measured NO typically exceeds 0.75 , while the resolution reflects that of the measurement. The bins for magnetic latitude run from -82.5 to $82.5^{\circ} \Lambda$ with a bin width of $5^{\circ} \Lambda$. Once the algorithm has sorted the individual measurements for the measurement day, it calculates the mean NO number density in each bin. Although the Odin orbit should ensure near-global coverage, on some days the data cover only a limited range of altitudes and latitudes due to gaps in the measurements. Figure 1 illustrates an example of the average NO number density for 1 August 2006. Maximum NO concentrations can be seen around -70 and $70^{\circ} \Lambda$ and reflect the locations of maximum auroral activity. With all measurement days, the resulting NO number density data comprise 442 individual days from January 2004 to April 2016, each containing 33 latitude and 5 altitude bins. Therefore, a 3-D matrix with the dimensions $442 \times 5 \times 33$ contains all the necessary information on NO. Although Odin has continued measuring subsequent to 2016, the period used already contains one solar cycle and is thus deemed sufficient for the analysis in this work. 


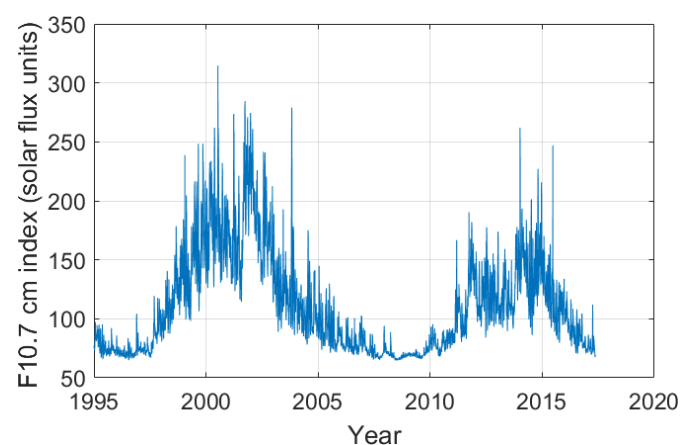

Figure 2. Daily mean $\mathrm{F} 10.7 \mathrm{~cm}$ flux over time in solar flux units $\left(10^{-22} \mathrm{~W} \mathrm{~m}^{-2} \mathrm{~Hz}^{-1}\right)$.

\subsection{Geomagnetic and solar indices}

Since auroral and solar activity create NO in the MLT, proxies that describe these two phenomena constitute key parts of SANOMA. In the search for appropriate proxies, this chapter introduces some of the most common ones.

Measurements of the irregular variations of the horizontal component of the Earth's magnetic field constitute an auroral activity index, the Kp index (Menvielle and Berthelier, 1991). It ranges from 0 to 9 on a quasi-logarithmic scale, with higher values corresponding to higher activity. It is derived every $3 \mathrm{~h}$ from a network of measurement stations located between $\sim 40$ and $60^{\circ} \mathrm{N}$ as well as at $\sim 40^{\circ} \mathrm{S}$ geographical latitude. A similar index, the Ap index, is exponentially proportional to the Kp index. Finally, the Ae index is another measure for auroral activity and some have suggested that it correlates more directly with NO in the MLT region than the Kp or Ap indices (Hendrickx et al., 2015). The Ae index derives from measurement stations closer to the magnetic poles than the Kp index (Menvielle et al., 2011). However, this study uses only the Kp index because the empirical model created with the Kp index explains a larger percentage of the variance of the original Odin SMR NO measurements than an empirical model using the Ae index. The Kp index is obtained from the National Oceanic and Atmospheric Administration (NOAA).

To describe solar activity, the $10.7 \mathrm{~cm}$ solar radio flux is among the most widely used indices. It constitutes a proxy for the incoming solar soft X-rays and is based on the solar radio emission in a $100 \mathrm{MHz}$ wide band centered around $2800 \mathrm{MHz}$ (Tapping and Detracey, 1990). This study uses the observed daily mean $10.7 \mathrm{~cm}$ from the NOAA. The total radiation flux centered around the Lyman- $\alpha$ line defines an alternative proxy for solar activity and originates from http://lasp.colorado.edu/lisird/data.html (last access: $8 \mathrm{Au}-$ gust 2018). Figure 2 shows the F10.7 cm flux over time. Over the measurement period of Odin SMR, solar activity decreased from 2003 to 2009 , subsequent to which it rose to reach a maximum in 2014 , followed by another decline. In

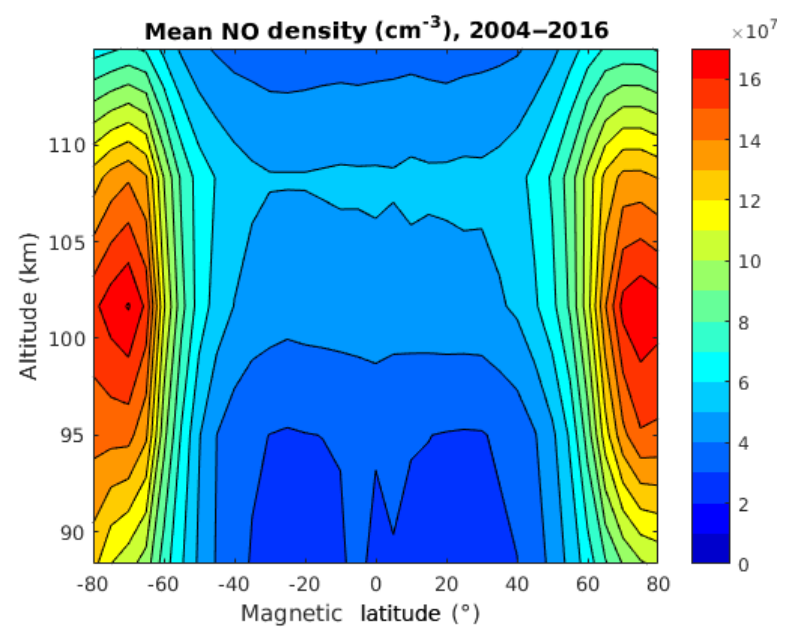

Figure 3. Mean NO density of NO measured by Odin SMR from 2004 to 2016.

the context of this work, the solar cycle is integral to understanding radiation-related variations of NO.

\section{SANOMA}

This section describes the method used to derive SANOMA from the original Odin SMR measurements. Section 3.1 presents the evidence on how various environmental conditions are linked to the amount of measured $\mathrm{NO}$ and presents the underlying equations of SANOMA. Section $3.2 \mathrm{com}-$ pares SANOMA as well as an empirical model derived from Odin SMR NO but using the principle of NOEM, with NO measured with Odin SMR.

\subsection{Linking environmental conditions and measurements to form SANOMA}

Figure 3 displays the mean NO from the Odin SMR dataset. Distinct maxima of up to $16 \times 10^{7} \mathrm{~cm}^{-3}$ at around $\pm 70^{\circ} \Lambda$ can be observed at an altitude of roughly $102 \mathrm{~km}$. Figure 4 shows the time series of the daily means of NO derived from the V3.0 Odin SMR data at the altitude-latitude bin centered at around (a) $102 \mathrm{~km}$ and $-70^{\circ} \Lambda$ and (b) $102 \mathrm{~km}$ and $0^{\circ} \Lambda$. Figure $4 \mathrm{a}$ displays strong seasonal variability, while the time series in Fig. 4b exhibits long-scale variability that can be associated with the solar cycle (Baker et al., 2001). The highest peaks in Fig. 4a are most likely produced by high levels of auroral activity. These enhancements are also linked to the seasonal variation, with the highest levels occurring during winter, during which NO created in the lower thermosphere is transported downwards in the polar vortex (Pérot et al., 2014).

To investigate the link between auroral activity and the NO number density, Fig. 5 zooms in on the year 2015 from the same time series as in Fig. 4 along with the daily mean of 

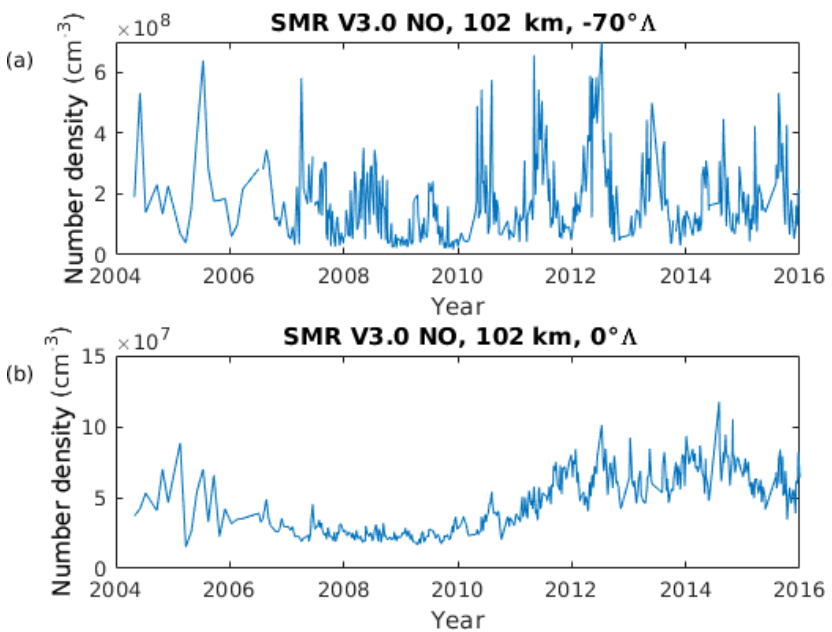

Figure 4. Daily mean NO density of Odin SMR NO at (a) $102 \mathrm{~km}$ and $-70^{\circ} \Lambda$ and (b) $102 \mathrm{~km}$ and $0^{\circ} \Lambda$, from 2004 to 2016 .

the (a) $\mathrm{Kp}$ and (b) $10.7 \mathrm{~cm}$ fluxes from 1 day prior to the measurements. Figure 5a suggests that the Kp index correlates with the amount of $\mathrm{NO}$ at the chosen location. Further, Fig. $5 \mathrm{~b}$ illustrates the link between tropical $\mathrm{NO}$ and the F10.7 cm flux.

Marsh et al. (2004) used the Kp index and F10.7 cm flux as proxies for auroral and solar activity, respectively. Marsh et al. (2004) used these two indices as well as solar declination as inputs for a model, NOEM, to calculate the variations of NO in the MLT. Understanding the theory behind NOEM is necessary to have a foundation upon which we build SANOMA. NOEM is based on principle component analysis of 2 years of measurements from the SNOE between 1998 and 2000, in which the variation of daily mean NO in time is described using EOFs in space, and their principal components (PCs) in time. In the study by Marsh et al. (2004), these PCs were replaced by polynomial fits to the planetary $\mathrm{K}$ index, the solar declination, and the $\mathrm{F} 10.7 \mathrm{~cm}$ flux. This led to the following equation:

$$
\begin{aligned}
\mathrm{NO}(\Lambda, h, t) & =\overline{\mathrm{NO}}(\Lambda, h)+\mathrm{EOF}_{1}(\Lambda, h) \cdot f_{1}(\mathrm{Kp}) \\
& +\mathrm{EOF}_{2}(\Lambda, h) \cdot f_{2}(\delta)+\mathrm{EOF}_{3}(\Lambda, h) \\
& \cdot f_{3}(\log (\mathrm{F} 10.7)),
\end{aligned}
$$

in which $f, h, t, \mathrm{Kp}, \delta$, and $\mathrm{F} 10.7$ denote a polynomial fit, the altitude, time, planetary $\mathrm{K}$ index, solar declination, and F10.7 cm flux, respectively. However, Kp, $\delta$, and F10.7 may be insufficient to describe the processes responsible for the creation and depletion of NO in the MLT region.

Figure 6 demonstrates a situation in which the Kp index may not suffice to model the NO number density near the magnetic pole. We use SOFIE measurements in this context since, contrary to Odin SMR, SOFIE measures on consecutive days. Figure $6 a$ and $b$ compare SOFIE NO with the $\mathrm{Kp}$ index at $102 \mathrm{~km}$ and $-75^{\circ} \Lambda$ during the Antarctic winter in 2013 and Antarctic summer in 2012 respectively.
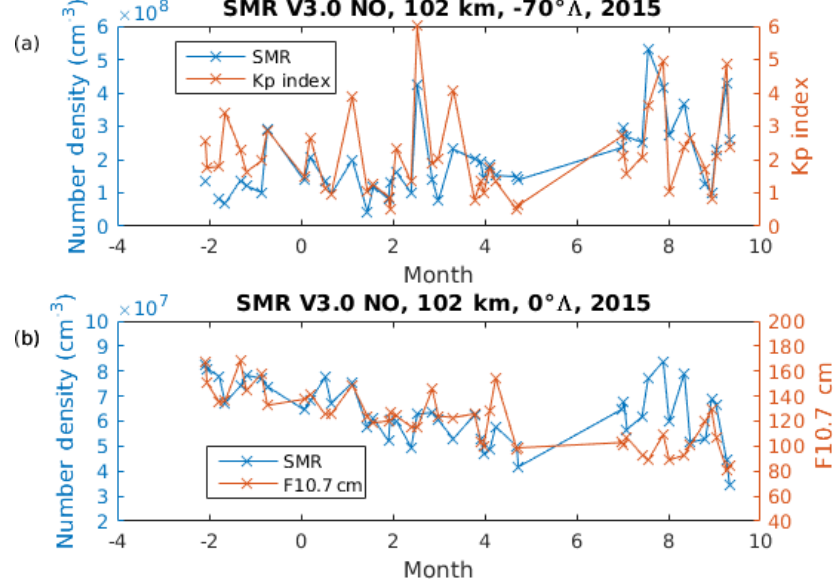

Figure 5. (a) Daily mean NO derived from Odin SMR at $102 \mathrm{~km}$ and $-70^{\circ}$ magnetic latitude with the $\mathrm{Kp}$ index (b) $102 \mathrm{~km}$ and $0^{\circ} \Lambda$ with the $\mathrm{F} 10.7 \mathrm{~cm}$ flux.
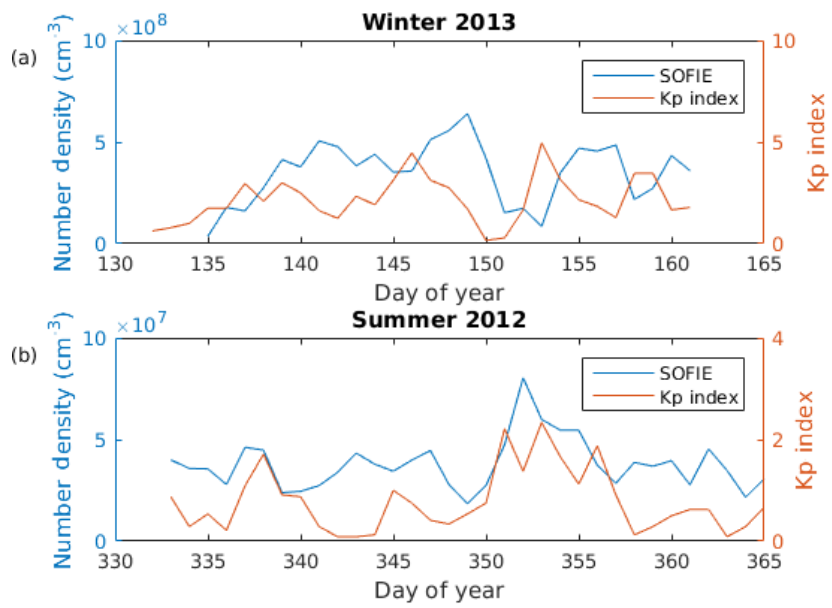

Figure 6. NO number density measured with SOFIE and Kp index over time for (a) $101 \mathrm{~km}$ altitude, $75^{\circ} \mathrm{S}$ magnetic latitude, winter 2013 , and (b) $101 \mathrm{~km}$ altitude, $75^{\circ} \mathrm{S}$ magnetic latitude, summer 2012.

Figure $6 \mathrm{a}$ and $\mathrm{b}$ display two key differences. Firstly, during summertime the NO number density is 1 order of magnitude lower than during winter. Additionally, Fig. $6 \mathrm{~b}$ suggests that SOFIE NO varies with little or no lag with respect to fluctuations in the Kp index. However, NO in Fig. 6a seems to have a lag of several days in comparison to the $\mathrm{Kp}$ index. For instance, the Kp index increases between days 142 and 146, while SOFIE NO follows an increase between days 146 and 149. Other examples can be seen between the increase in the Kp index on days 151 and 157, as well as the corresponding increases in NO on days 153 and 158. Such a lag could be due to the longer lifetime of NO in dark conditions. Although Fig. 6 offers no conclusive evidence of a major difference in the behavior of measured $\mathrm{NO}$ with respect to the Kp index, it does warrant a need for further investigation. Perhaps the fact 
Table 1. Parameter $n$ in Eqs. (2) and (3) as a function of solar declination $(\delta)$.

\begin{tabular}{lll}
\hline$n$ & $\operatorname{com}_{1}$ & $\operatorname{com}_{2}$ \\
\hline 3 & $\delta>0$ & $\delta<0$ \\
4 & $-5<\delta \leq 0$ & $5>\delta \geq 0$ \\
6 & $-10<\delta \leq-5$ & $10>\delta \geq 5$ \\
8 & $-15<\delta \leq-10$ & $15>\delta \geq 10$ \\
12 & $-20<\delta \leq-15$ & $20>\delta \geq 15$ \\
22 & $\delta \leq-20$ & $\delta \geq 20$ \\
\hline
\end{tabular}

that NOEM disregards any effect of the previous Kp indices has an effect on the accuracy of the final model. This is why we propose two additional indices that take into account the $\mathrm{Kp}$ index on prior days as well. These are defined as:

$\mathrm{com}_{1}=\sum_{d=2}^{n} \mathrm{Kp}_{d} \cdot e^{-(d-2) / 5} \cdot \frac{-\delta+23.4}{46.8}$

$\mathrm{com}_{2}=\sum_{d=2}^{n} \mathrm{Kp}_{d} \cdot e^{-(d-2) / 5} \cdot \frac{\delta+23.4}{46.8}$

in which $\mathrm{Kp}_{d}$ is the $\mathrm{Kp}$ index where $d$ indicates the number of days prior to the simulated day, and $n$ is a constant that depends on the solar declination. A solar declination of $23.4^{\circ}$ corresponds to summer solstice in the Northern Hemisphere. During this time $\operatorname{com}_{1}$ is equal to zero, and the solar declination term in $\operatorname{com}_{2}$ is equal to one, while the opposite holds true for the winter solstice of the Northern Hemisphere when the solar declination is $-23.4^{\circ}$. Therefore, $\operatorname{com}_{1}$ pertains to an NO buildup from previous days in dark conditions in the Northern Hemisphere, while com $_{2}$ has the same function for the Southern Hemisphere. Equations (2) and (3) assume that the influence of NO from previous days reduces exponentially with an increasing number of days prior to measurement. The constant $n$ for $\operatorname{com}_{1}$ and com 2 depends on the solar declination, as listed in Table 1.

The parameter $n$ regulates the number of days from which the $\mathrm{Kp}$ index is taken into account by $\operatorname{com}_{1}$ and $\operatorname{com}_{2}$. In winter, when sunlight exposure is low, NO is not photochemically destroyed. Auroral activity therefore affects the measured NO over longer time periods, and we expect a larger value for $n$. These exact values for $n$, given in Table 1 , are the results of an iteration scheme in Eqs. (2) and (3). This iteration scheme contained two variables: the parameter $n$ as a function of the solar declination bins in Table 1, and the factor in the denominator of the exponential, $e^{-d / 5}$, which describes how quickly the influence of the Kp index from previous days diminishes. The criterion for finding these values was to maximize the adjusted $R^{2}$ averaged over the entire spatial domain of the resulting empirical model compared to the original measurements, described later on in Sect. 3.2 and depicted in Fig. 11c. With an initial guess of $n$ for the various solar declination bins of $3,4,5,7,10$, and 12 , the denomi-

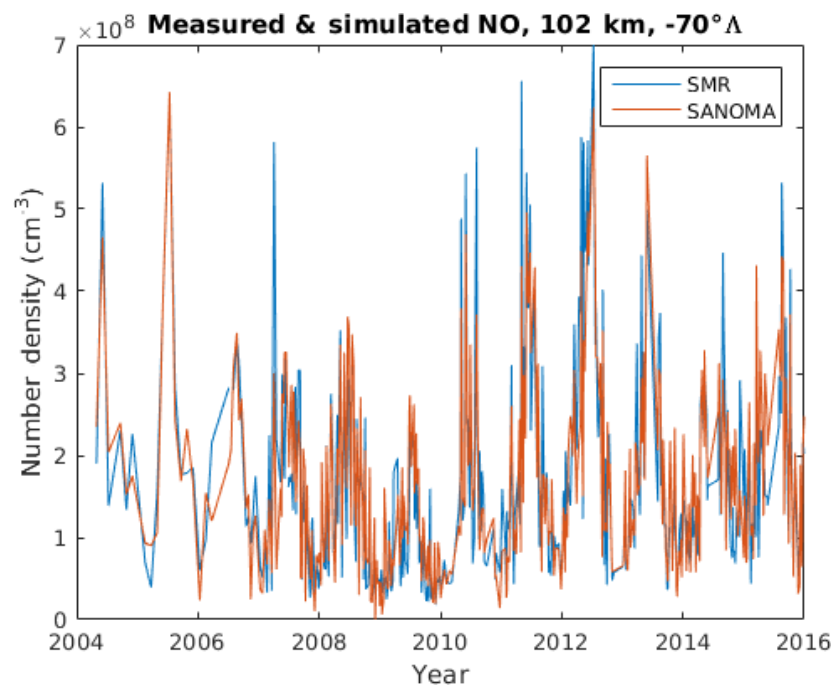

Figure 7. SMR-measured and SANOMA-simulated time series of $\mathrm{NO}$ at $102 \mathrm{~km}$ and $-70^{\circ} \Lambda$.

nator that maximizes the adjusted $R^{2}$ value in Fig. 11 is 5 . Similarly, with the now-determined denominator, each solar declination bin was optimized individually, such that the adjusted $R^{2}$ averaged over the entire spatial domain in Fig. 11 would reach a maximum. This iteration resulted in the values presented in Table 1. Section 3.2 demonstrates that these two compound indices lead to a significant improvement in the model.

SANOMA uses the three indices from NOEM and the two indices defined in Eqs. (2) and (3) to build a multivariate linear fit. The simulated NO for each altitude-latitude bin as a function of time becomes

$$
\begin{aligned}
\mathrm{NO}(\Lambda, h, t) & =\mathrm{Kp}(t) \cdot c_{1}+\operatorname{dec}(t) \cdot c_{2}+\log (\mathrm{F} 10.7 \mathrm{~cm}(t)) \cdot c_{3} \\
& +\operatorname{com}_{1}(\mathrm{Kp}, \operatorname{dec}) \cdot c_{4}+\operatorname{com}_{2}(\mathrm{Kp}, \operatorname{dec}) \cdot c_{5}+C,
\end{aligned}
$$

in which the $\mathrm{Kp}$ index and the logarithm of the F10.7 cm flux both have a lag of 1 day for the best fit. This lag is in accordance with previous similar studies (Hendrickx et al., 2015; Marsh et al., 2004; Solomon et al., 1999). Solomon et al. (1999) attribute this lag to the 1-day lifetime of NO. Taking the logarithm of the F10.7 cm flux instead of the flux itself results in a better fit between SANOMA and Odin SMR. This observation agrees with the findings of Marsh et al. (2004) and Fuller-Rowell (1993). The indices $c$ are obtained as an output of a multivariate linear fit function called "regress" in MATLAB 2015b, in which a matrix containing all of the input indices as a function of time, and a corresponding matrix containing the measured NO time series in a given altitude and latitude bin, constitute the two inputs. Figure 7 shows the measured and simulated time series of NO for $102 \mathrm{~km}$ and $-70^{\circ} \Lambda$. Although SANOMA generally follows the SMR measurements, it misses some of the highest peaks of NO. Either these peaks are results of random variation of the measurements, or SANOMA fails to simulate some physical or 

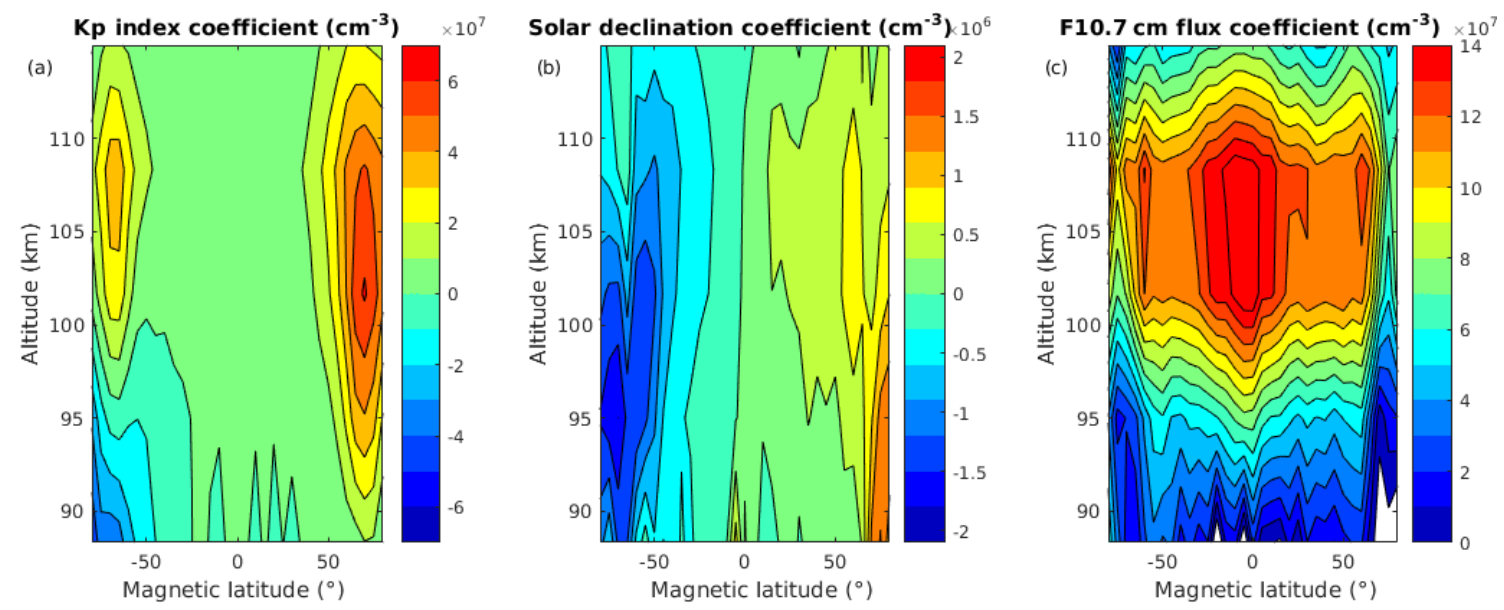

Figure 8. The coefficients of the (a) Kp index, (b) Solar declination, and (c) F10.7 cm flux, in Eq. (4).

chemical process that would result in such peaks of NO. One such effect could be the dynamics of the MLT region, which would transport NO.

The complete SANOMA model comprises of a total of 165 individual multivariate linear fits, one for each altitudelatitude bin. The coefficients of these fits indicate which of the input indices influence NO at the various locations. Figure $8 \mathrm{a}-\mathrm{c}$ present the coefficients of the multivariate linear fits for the $\mathrm{Kp}$ index, solar declination, and $\log (\mathrm{F} 10.7 \mathrm{~cm})$ flux, respectively. These figures offer an insight into where each of the physical drivers influences the NO number density the most. The effect of geomagnetic activity seems to be strongest around $\pm 70^{\circ} \Lambda$, while the solar radiation affects $\mathrm{NO}$ over the latitude range within $\pm 70^{\circ} \Lambda$ in the altitudes from 100 to $110 \mathrm{~km}$. Figure $8 \mathrm{a}-\mathrm{c}$ are also reminiscent of the EOFs obtained by Marsh et al. (2004). Furthermore, Fig. 8b shows the antisymmetric effect of season on contributing to either an increase or decrease in NO, as the coefficient changes sign from negative in the Southern Hemisphere to positive in the Northern Hemisphere. Finally, Fig. 9a and $\mathrm{b}$ depict the coefficients corresponding to the new indices, $\mathrm{com}_{1}$ and $\mathrm{com}_{2}$, respectively. The two exhibit maxima at roughly $95 \mathrm{~km}$ in altitude close to the northern and southern magnetic poles. Figure 9 indicates that the indices function as planned as com $_{1}$ significantly deviates from zero only in the Northern Hemisphere, while the same is true for $\operatorname{com}_{2}$ in the Southern Hemisphere. The entire set of coefficients can be downloaded from http://odin.rss.chalmers.se (last access: 15 September 2018).

\subsection{Comparing SANOMA to Odin SMR-measured NO}

This section compares NO simulated with SANOMA with the original SMR-measured NO to confirm that the model has been successfully built. SANOMA has a resolution of $6.66 \mathrm{~km}$ in altitude and $5^{\circ} \Lambda$ in latitude. Figure 10 illustrates the mean of the difference (in $\mathrm{cm}^{-3}$ ) of the time series of
SMR and SANOMA NO at each location. The largest mean difference is $-8 \times 10^{-8} \mathrm{~cm}^{-3}$. Considering that the actual measured number density of NO is within the order of magnitude $10^{7} \mathrm{~cm}^{-3}$, this difference can be considered negligible and the result of numerical error in the creation of the model.

To explore the added value of the two new indices and the SANOMA equation, Fig. 11 illustrates the adjusted coefficient of determination, denoted $R^{2}$, of three empirical models based on Odin SMR NO measurements. These models are (a) a model built up according to Eq. (1), called SMRNOEM, as a function of magnetic latitude and altitude, (b) a model built with Eq. (4) but without the compound indices, and (c) with Eq. (4). The $R^{2}$ value represents the percentage of the variance in the original SMR dataset that each model can explain. Autocorrelation in the residuals was tested using the Ljung-Box $Q$ test (Ljung and Box, 1978). It was found to be present but reasonable at low and middle latitudes above $95 \mathrm{~km}$, and negligible everywhere else. We can therefore consider that the $R^{2}$ values give a relatively good estimation of the explained variance. In Fig. 11 from left to right, we can observe an increasing trend in which the mean $R^{2}$ values in each subplot is $0.506,0.541$, and 0.643 . Figure $11 \mathrm{~b}$ demonstrates that using a multivariate linear method instead of EOF analysis increases the $R^{2}$ somewhat in comparison to Fig. 11a, but the more obvious improvement is provided by the inclusion of $\mathrm{Kp}$ index information from earlier days, as illustrated by Fig. 11c. The most striking difference between Fig. 11b and $c$ is the great increase in the explained variance close to the magnetic poles and lower down in altitude, brought by the compound indices $\operatorname{com}_{1}$ and $\operatorname{com}_{2}$. This improvement can be explained by the fact that these two indices take the lifetime of upper-atmospheric NO into account, hence yielding more accurate results in the polar regions in which the accumulation of NO in the absence of sunlight plays an important role. Using Eq. (4) to build an empirical model therefore increases the overall explained 

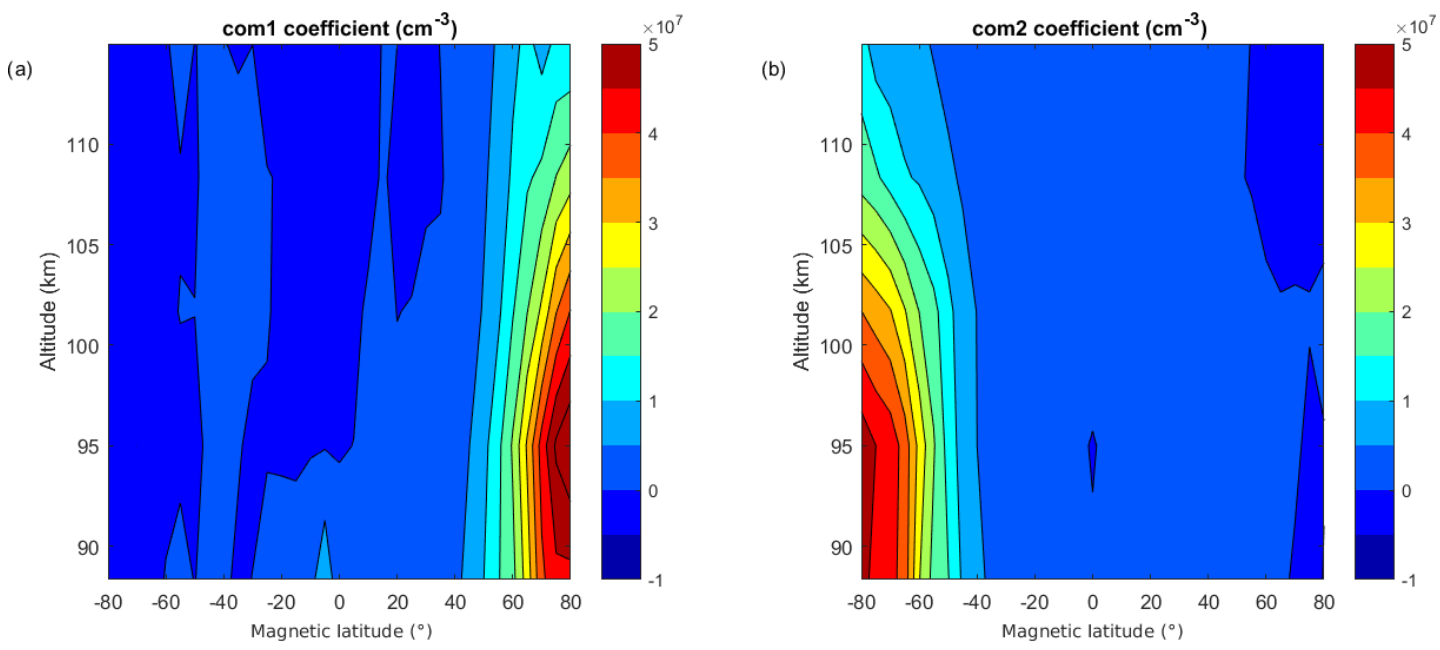

Figure 9. The coefficients corresponding to the (a) com 1 and (b) com 2 indices.

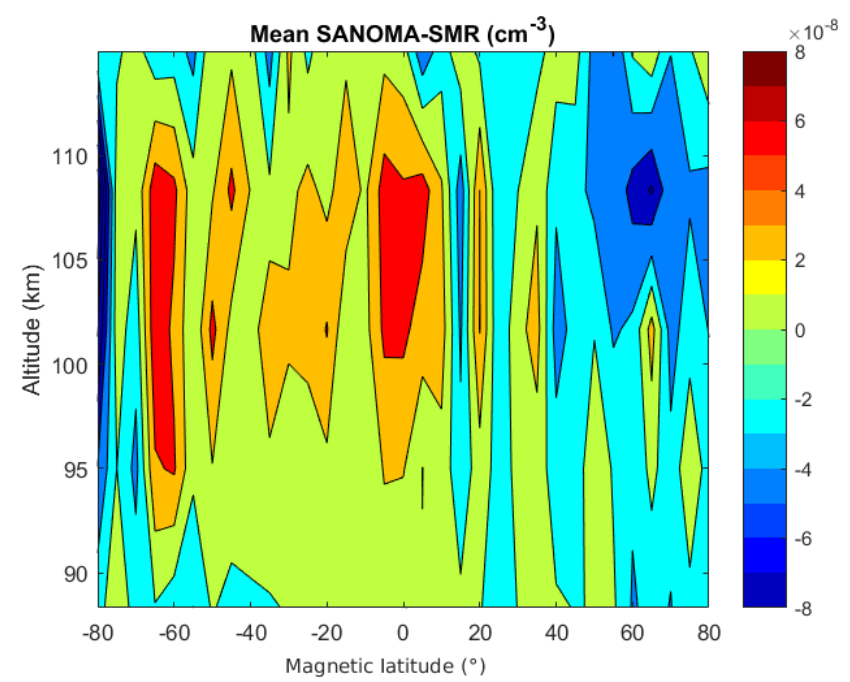

Figure 10. Mean of the differences (in $\mathrm{cm}^{-3}$ ) between the time series of SANOMA-simulated and SMR-measured NO.

variance by $13 \%$, and by up to $40 \%$ near the poles. The figures imply that Eq. (4) would describe the variation of NO best around the magnetic poles, in which geomagnetic activity dominates its variation. Although the adjusted $R^{2}$ attains 0.9 close to the magnetic poles and exceeds 0.5 in most areas, values down to 0.1 indicate that SANOMA fails to accurately simulate the variability of $\mathrm{NO}$ at magnetic latitudes closer to the equator than $\pm 40^{\circ}$ and below altitudes of roughly $95 \mathrm{~km}$.

So far we have presented how well SANOMA explains SMR measurements. However, the SMR measurements themselves include measurement error and hence a model will be unable to perfectly reproduce the measurements. We can attempt to separate the discrepancy between SANOMA and SMR into two parts: the measurement error from Odin SMR and the modeling error from SANOMA. Having an un- derstanding of the error of SANOMA can help to assess the reliability of its simulations. Assuming that all errors are normally distributed, we estimate the variance of the modeling error with

$\sigma_{\text {SANOMA }}^{2}=\sigma_{\text {total }}^{2}-\sigma_{\text {OdinSMR }}^{2}$

in which $\sigma_{\text {SANOMA }}^{2}, \sigma_{\text {total }}^{2}$, and $\sigma_{\text {OdinSMR }}^{2}$ are the estimated variances of the model error, total error, and measurement error, respectively. For each location, we estimate $\sigma_{\text {total }}^{2}$ as the variance of the time series of SANOMA-SMR. The mean of the daily means of the known measurement error constitutes $\sigma_{\text {OdinSMR }}^{2}$. In some cases, $\sigma_{\text {SANOMA }}^{2}$ is close to zero, or slightly negative. If this occurs, $\sigma_{\text {SANOMA }}^{2}$ is set to zero, so we can calculate the square root of the variance to yield the standard deviation of the modeling error. Figure 12 illustrates the standard deviation of the modeling error in absolute and relative values. Figure $12 \mathrm{~b}$ suggests that the highest relative modeling error is located at the lowest altitudes. This is not surprising as it corresponds to the altitude range where we find lower values of NO number densities. Moreover, the transport of NO starts to play a non-negligible role in this region, affecting the number density of NO. SANOMA includes no parameter to account for this effect, possibly explaining the higher relative standard deviation of the modeling error.

\section{Assessment of SANOMA and NOEM}

So far, we have presented SANOMA, its underlying principle, and a comparison of its simulations with NO measured by Odin SMR. This section evaluates the performance of SANOMA and NOEM by comparing simulated NO number density with measured NO from the four independent instruments, SOFIE, SCIAMACHY, ACE-FTS, and MIPAS. SANOMA can be seen as a tool to compare the SMR dataset with the other data, and therefore these comparisons can pro- 

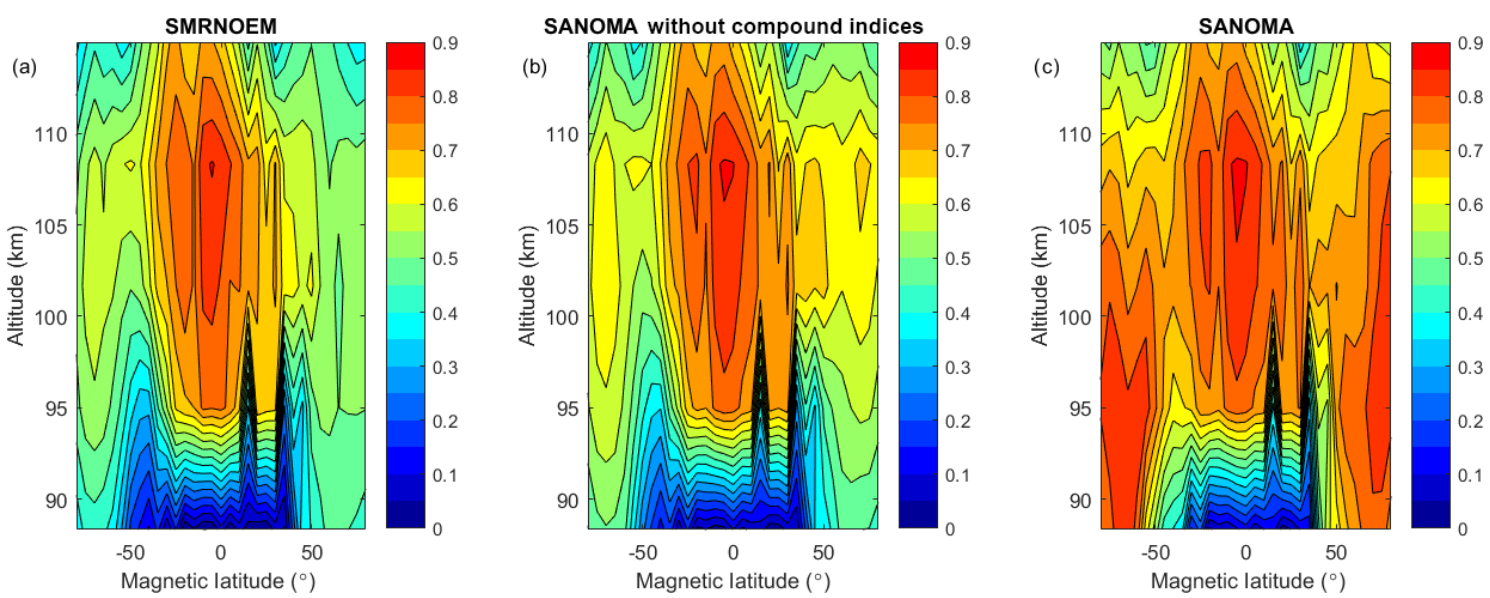

Figure 11. Adjusted $R^{2}$ between SMR and an empirical model from Odin SMR NO using (a) Eq. (1), (b) Eq. (4) without $\operatorname{com}_{1}$ or $\operatorname{com}_{2}$, and (c) Eq. (4).
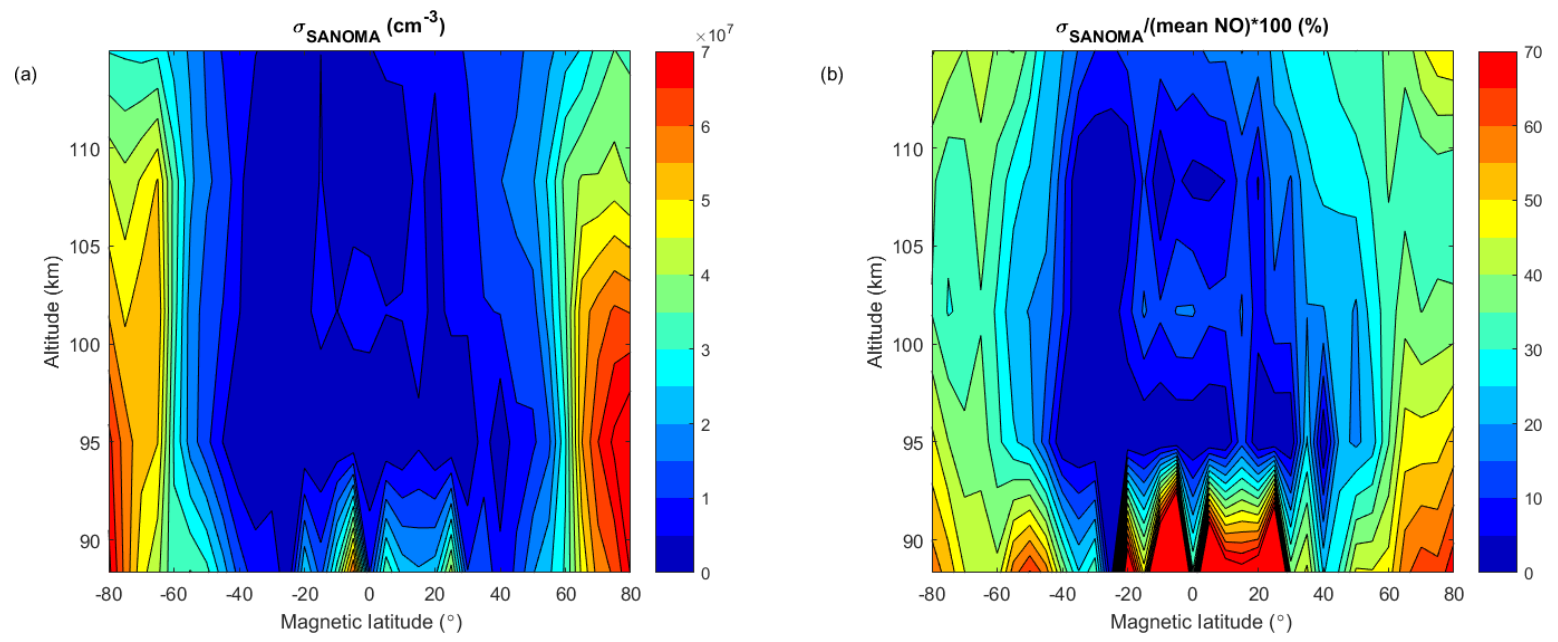

Figure 12. (a) Standard deviation of the modeling error. (b) Standard deviation of the modeling error relative to the mean NO.

vide valuable information regarding the accuracy of SMRNO measurements. For an overview, Table 2 lists the underlying techniques behind the instruments as well as the time and regions of operation.

SANOMA has a resolution of $6.66 \mathrm{~km}$ in altitude and $5^{\circ} \Lambda$ in latitude while NOEM has corresponding resolutions of $3.33 \mathrm{~km}$ and $5^{\circ} \Lambda$. For direct comparison, we average two adjacent NOEM altitude bins to result in an altitude resolution of $6.66 \mathrm{~km}$. To prepare each dataset comparison with these models, an algorithm sorts the NO measurements from each instrument into the same bins as in SANOMA and calculates daily average NO number density. The following four subsections present the comparisons of SANOMA and NOEM to the four independent instruments, while Sect. 4.5 summarizes these results.

\subsection{SOFIE}

This section compares the SANOMA- and NOEM-simulated NO number density with Level 2 V1.3 SOFIE measurements (Gordley et al., 2009) (available at http://sofie.gats-inc. com, last access: 10 December 2017) between 102 and $115 \mathrm{~km}$. These altitudes reflect the range in which NOEM, SANOMA, and SOFIE all overlap. According to Fig. 13, especially prior to 2011, NOEM-simulated NO exceeds that of both SOFIE-measured and SANOMA-simulated NO. A possible cause for this effect is discussed in Sect. 4.5. Additionally, the SOFIE measurements show high peaks of NO, which are partially absent in SANOMA, and completely absent in NOEM. The SANOMA time series seems to generally agree better with the SOFIE measurements than NOEM.

To examine the accuracy of SANOMA and NOEM as a function of magnetic latitude and altitude, Fig. 14 depicts the median of the difference between the simulated NO and 
Table 2. Overview of all the compared NO datasets.

\begin{tabular}{lllll}
\hline Instrument & Period & Latitudes & Technique & Wavelength \\
\hline SMR & $2003-$ & $82^{\circ} \mathrm{S}-82^{\circ} \mathrm{N}$ & Microwave emission & $544 \mu \mathrm{m}$ \\
SNOE & $1998-2000$ & $82^{\circ} \mathrm{S}-82^{\circ} \mathrm{N}$ & UV scattering & $215,237 \mathrm{~nm}$ \\
SOFIE & $2007-$ & $80-60^{\circ} \mathrm{S}, 60-80^{\circ} \mathrm{N}$ & Solar occultation & $5.316 \mu \mathrm{m}$ \\
SCIAMACHY & $2008-2012$ & $88.75^{\circ} \mathrm{S}-88.75^{\circ} \mathrm{N}$ & UV scattering & $230-314 \mathrm{~nm}$ \\
ACE & $2004-$ & $85^{\circ} \mathrm{S}-85^{\circ} \mathrm{N}$ & Solar occultation & $5.18-5.43 \mu \mathrm{m}$ \\
MIPAS & $2005-2012$ & $90^{\circ} \mathrm{S}-90^{\circ} \mathrm{N}$ & Infrared emission & $5.3 \mu \mathrm{m}$ \\
\hline
\end{tabular}

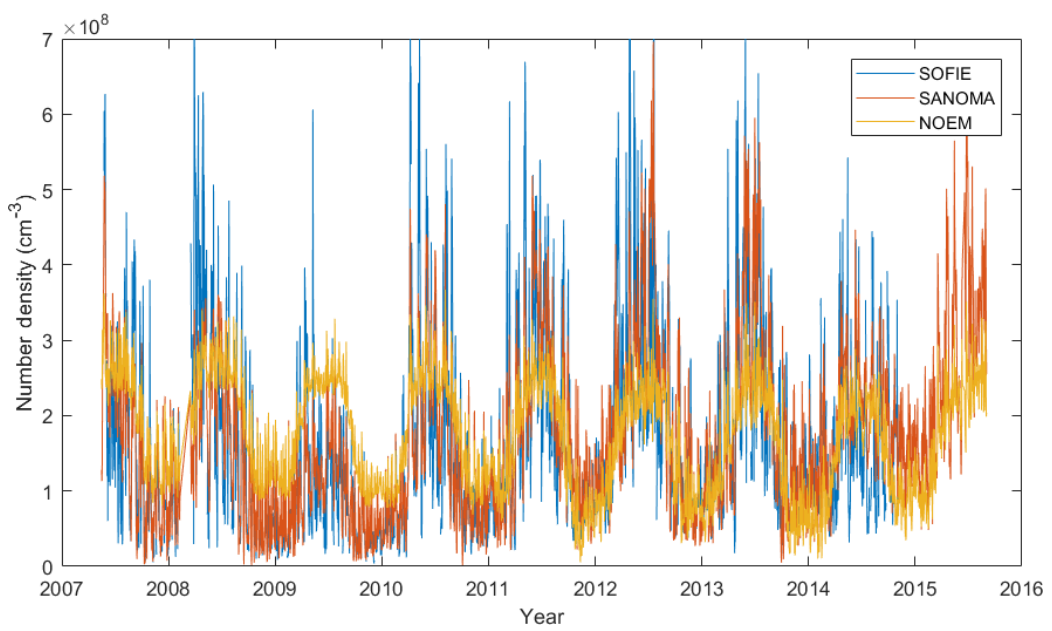

Figure 13. Time series of NO number density measured with SOFIE over the entire measurement period as well as simulated NO with SANOMA and NOEM, $102 \mathrm{~km}$ altitude, $-70^{\circ} \Lambda$.
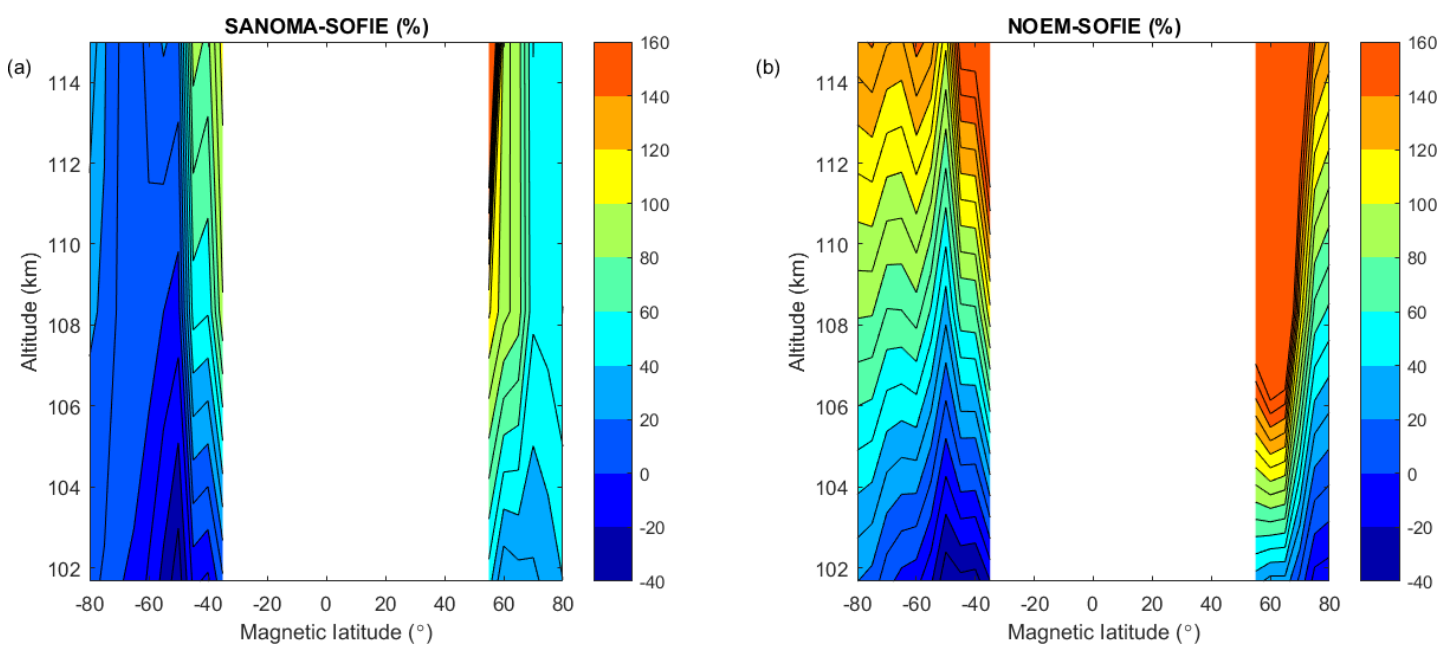

Figure 14. (a) Median difference between SANOMA and SOFIE as a percentage of mean SOFIE NO number density. (b) Median difference between NOEM and SOFIE as a percentage of mean SOFIE NO number density.

SOFIE as a percentage of the mean SOFIE number density. Although SOFIE predominantly measures at geographic latitudes between 60 and $80^{\circ}$ in both hemispheres, some measurements from the Southern Hemisphere originate from as low as $40^{\circ} \Lambda$ due to a changing orbit and greater offset be- tween the geomagnetic and geographic poles in the Southern Hemisphere. Generally, the difference between SANOMA and SOFIE lies within $\pm 40 \%$ in the region from 60 to $80^{\circ} \Lambda$ in both hemispheres while the NOEM-modeled NO exceeds SOFIE with up to $160 \%$. 

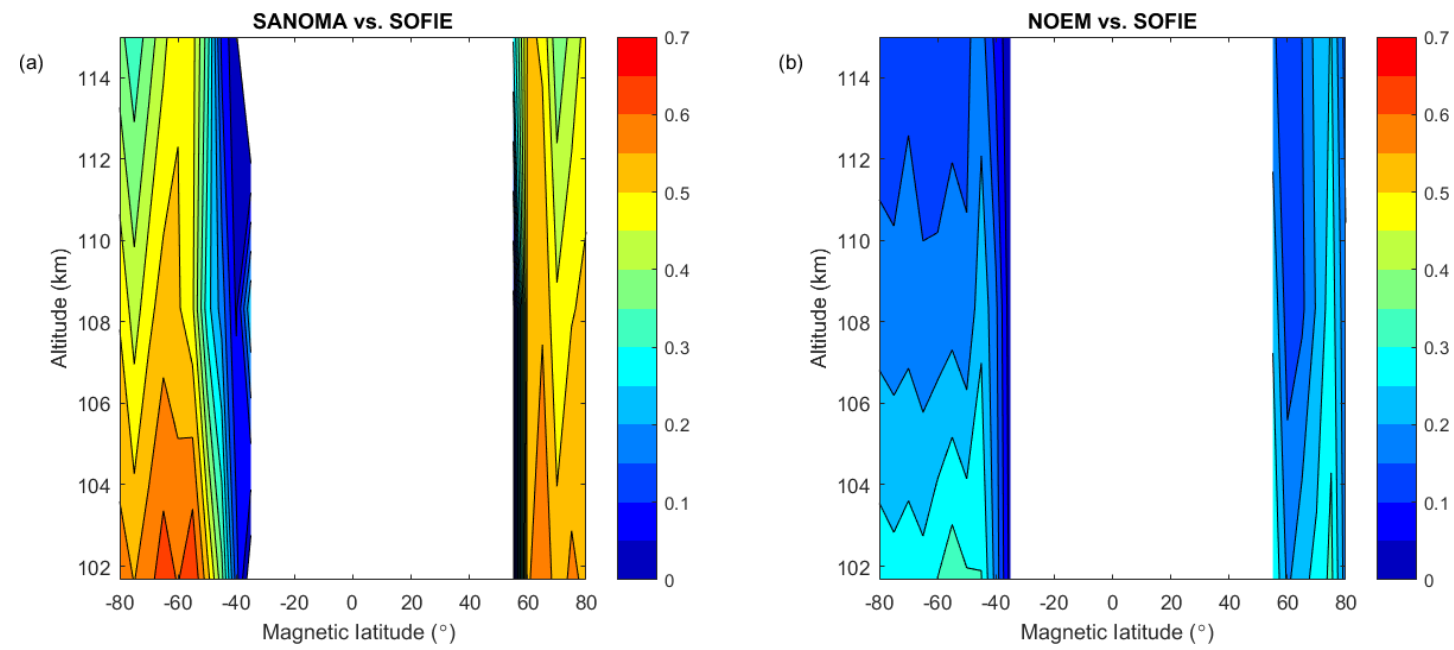

Figure 15. (a) Adjusted $R^{2}$ of linear fits between SANOMA and SOFIE NO number density. (b) Adjusted $R^{2}$ of linear fits between NOEM and SOFIE NO number density.

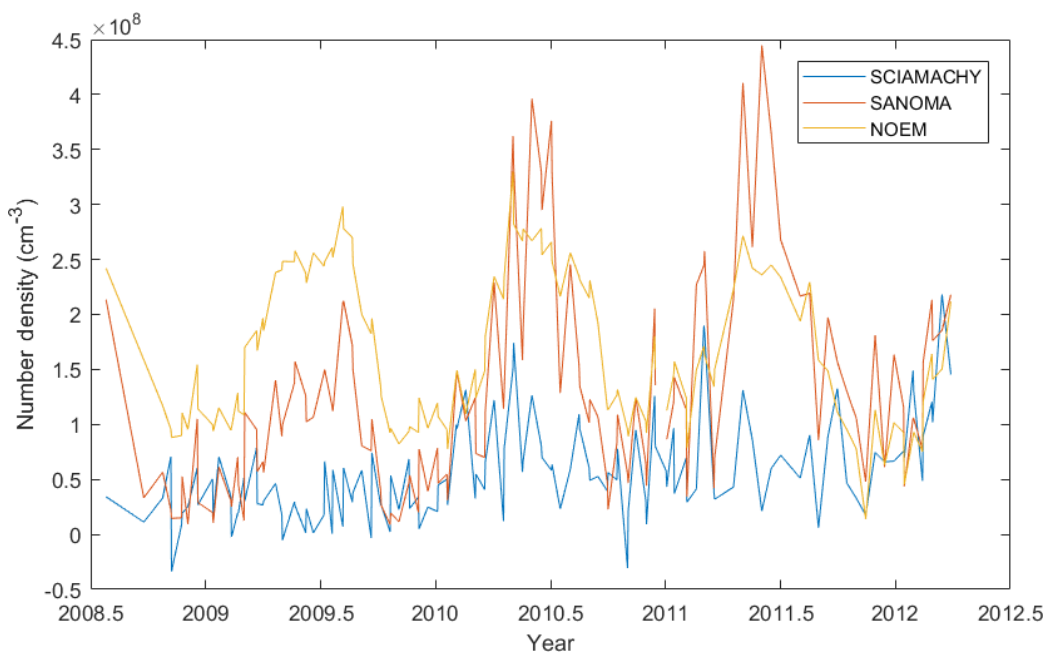

Figure 16. Time series of NO number density measured with SCIAMACHY and simulated with SANOMA as well as NOEM, $102 \mathrm{~km}$ altitude, $-70^{\circ} \Lambda$.

To assess the amount of variation that each model captures of the original SOFIE data, Fig. 15 presents the $R^{2}$ values of linear fits between SANOMA and SOFIE as well as NOEM and SOFIE, respectively. Whereas SANOMA exhibits up to $0.65 R^{2}$ at $-70^{\circ} \Lambda$ and $102 \mathrm{~km}$, NOEM falls significantly shorter with a maximum $R^{2}$ value of 0.35 at $-55^{\circ} \Lambda$ and $102 \mathrm{~km}$. Furthermore, Fig. 15 emphasizes that SANOMA outperforms NOEM at all altitudes in the auroral zone of 60 to $80^{\circ} \Lambda$ in both hemispheres and that SANOMA captures more variability of the SOFIE measurements in the Southern than in the Northern Hemisphere.

\subsection{SCIAMACHY}

This section compares the SANOMA- and NOEM-simulated NO number density with v1.8.1 SCIAMACHY (Bender et al., 2013) measurements of $\mathrm{NO}$ in the altitudes from 102 to $115 \mathrm{~km}$. Figure 16 draws the time series of SCIAMACHYmeasured, as well as SANOMA- and NOEM-simulated NO for $102 \mathrm{~km}$ and $-70^{\circ} \Lambda$. As in Fig. 13, NOEM NO exceeds that of both SANOMA and SCIAMACHY, whereas SANOMA follows SCIAMACHY-measured NO more accurately over the entire measurement period. Another clear feature is that SANOMA NO increases significantly more than SCIAMACHY NO during Antarctic winter. One possible explanation is that SCIAMACHY only measures daytime NO, whereas the Odin SMR data that resulted in SANOMA also included measurements from the polar night, during which the NO number density is enhanced.

Figure $17 \mathrm{a}$ and $\mathrm{b}$ display the mean difference between SANOMA and SCIAMACHY as well as NOEM and SCIA- 

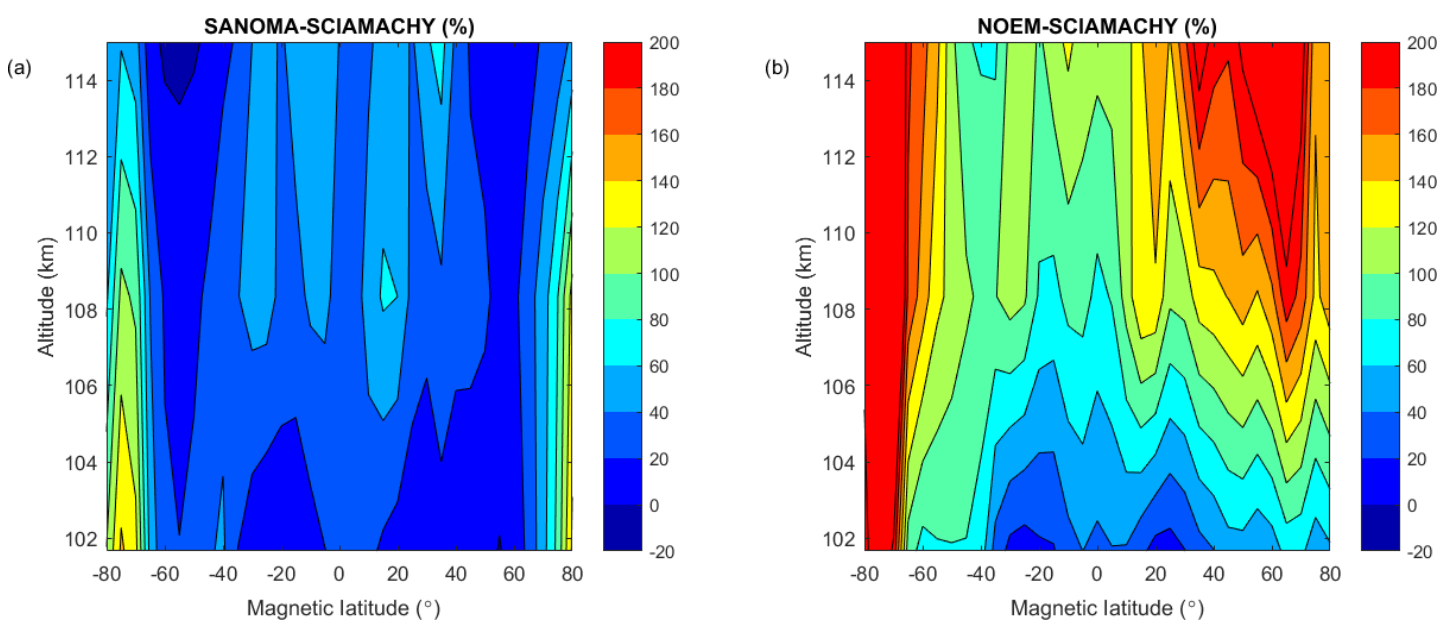

Figure 17. (a) Median difference between SANOMA and SCIAMACHY as a percentage of mean SCIAMACHY NO number density. (b) Median difference between NOEM and SCIAMACHY as a percentage of mean SCIAMACHY NO number density.
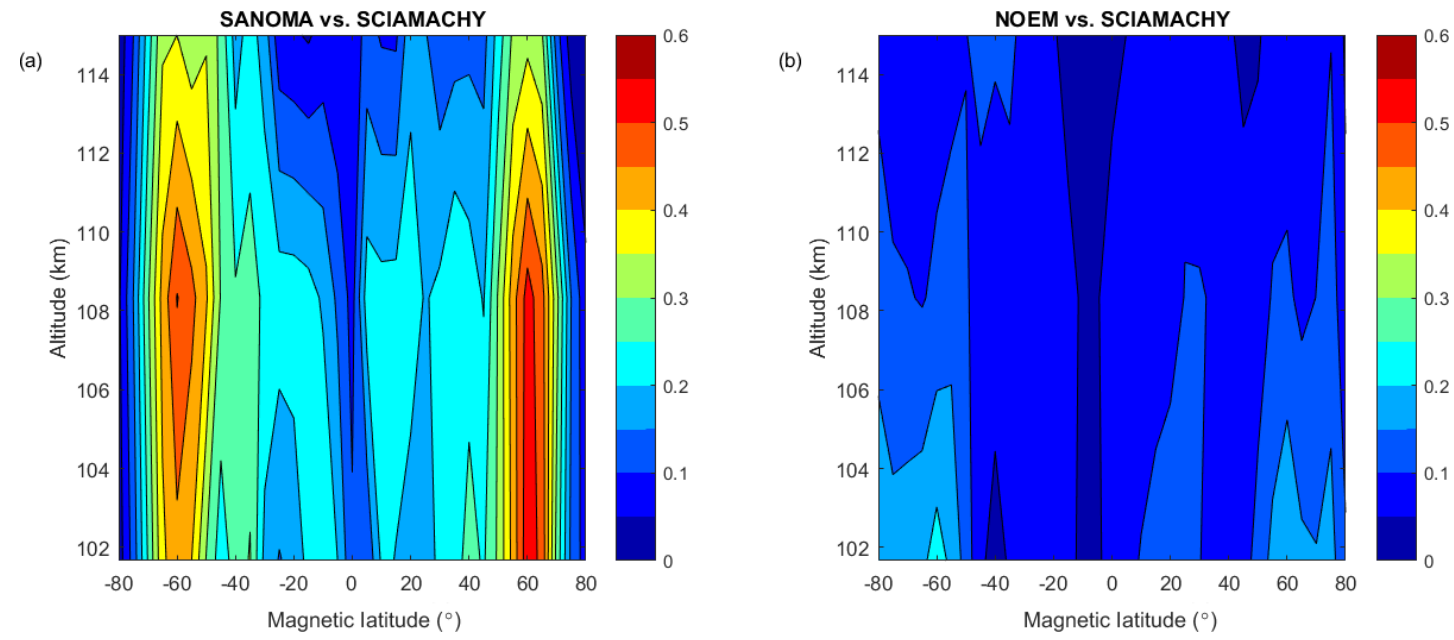

Figure 18. (a) Adjusted $R^{2}$ of a linear fit between SANOMA and SCIAMACHY NO number density. (b) Adjusted $R^{2}$ of a linear fit between NOEM and SCIAMACHY NO number density.

MACHY as a percentage of the mean SCIAMACHY number density. NOEM NO exceeds SCIAMACHY with over $200 \%$ while SANOMA reaches maximum differences up to $150 \%$ at $-70^{\circ} \Lambda$ and $102 \mathrm{~km}$.

As can be seen in Fig. 18a and b, SANOMA reaches maximum $R^{2}$ values of roughly 0.5 in the areas of high auroral activity while NOEM attains only 0.25 at $102 \mathrm{~km}$ and $-60^{\circ} \Lambda$. The results suggest that SANOMA captures significantly more variability of the SCIAMACHY dataset than NOEM.

\subsection{ACE}

This section compares the SANOMA and NOEM simulated NO number densities with V3.5 ACE measurements (Bernath et al., 2005) between 102 and $108 \mathrm{~km}$. Quality filtering of the ACE NO measurements constitutes the reason for the upper limit of the altitude in these comparisons. Figure 19 provides an overview of nearly one entire solar cycle of ACE, SANOMA, and NOEM NO. It can be seen that both models miss the highest spikes of NO in the ACE measurements, although SANOMA manages to capture several between 2005 and 2012. Figure 20a suggests that the difference between SANOMA and ACE is generally zero or positive above $105 \mathrm{~km}$ with a maximum difference of $60 \%$ within $30^{\circ} \Lambda$ of the magnetic equator at $108 \mathrm{~km}$. Negative differences can be observed below $105 \mathrm{~km}$, with a minimum of $-50 \%$ near the magnetic equator at $102 \mathrm{~km}$. On the contrary, Fig. 20b shows that the difference between NOEM and ACE is positive at nearly all locations, with a maximum of $160 \%$ at $20^{\circ} \mathrm{N}$ magnetic latitude at $108 \mathrm{~km}$. The patterns in Fig. 20 could be due to the different height at which each model places the maximum NO. The maximum of NO num- 
Table 3. Adjusted $R^{2}$ averaged over the entire altitude range $(102-115 \mathrm{~km})$ over three latitude bands: southern high latitudes, tropics, and northern high latitudes, as well as the average of the mean percentage differences over these three domains between (a) NOEM, (b) SMRNOEM, and (c) SANOMA, and the various instruments.

\begin{tabular}{lrrr|rrr|rr|rr|rrr|rr}
\hline & \multicolumn{2}{c|}{$R^{2}\left(-75\right.$ to $\left.-55^{\circ} \Lambda\right)$} & \multicolumn{2}{c|}{$R^{2}\left(-30\right.$ to $\left.30^{\circ} \Lambda\right)$} & \multicolumn{3}{|c|}{$R^{2}\left(55\right.$ to $\left.75^{\circ} \Lambda\right)$} & \multicolumn{3}{|c}{ Mean difference (\%) } \\
\cline { 2 - 12 } Instrument & $\mathrm{a}$ & $\mathrm{b}$ & $\mathrm{c}$ & $\mathrm{a}$ & $\mathrm{b}$ & $\mathrm{c}$ & $\mathrm{a}$ & $\mathrm{b}$ & $\mathrm{c}$ & $\mathrm{a}$ & $\mathrm{b}$ & $\mathrm{c}$ \\
\hline SMR & 0.287 & 0.509 & 0.646 & 0.544 & 0.704 & 0.732 & 0.356 & 0.487 & 0.702 & 42.8 & 2.2 & 0.1 \\
SOFIE & 0.193 & 0.307 & 0.500 & $\mathrm{n} / \mathrm{a}$ & $\mathrm{n} / \mathrm{a}$ & $\mathrm{n} / \mathrm{a}$ & 0.212 & 0.207 & 0.417 & 112.9 & 38.6 & 37.8 \\
SCIAMACHY & 0.124 & 0.292 & 0.317 & 0.069 & 0.148 & 0.161 & 0.118 & 0.095 & 0.322 & 117.7 & 53.6 & 35.8 \\
ACE & 0.169 & 0.423 & 0.514 & 0.246 & 0.469 & 0.510 & 0.272 & 0.381 & 0.577 & 69.1 & 33.8 & 27.2 \\
MIPAS & 0.206 & 0.350 & 0.426 & 0.291 & 0.581 & 0.621 & 0.197 & 0.342 & 0.571 & 67.5 & 29.2 & 18.3 \\
\hline
\end{tabular}

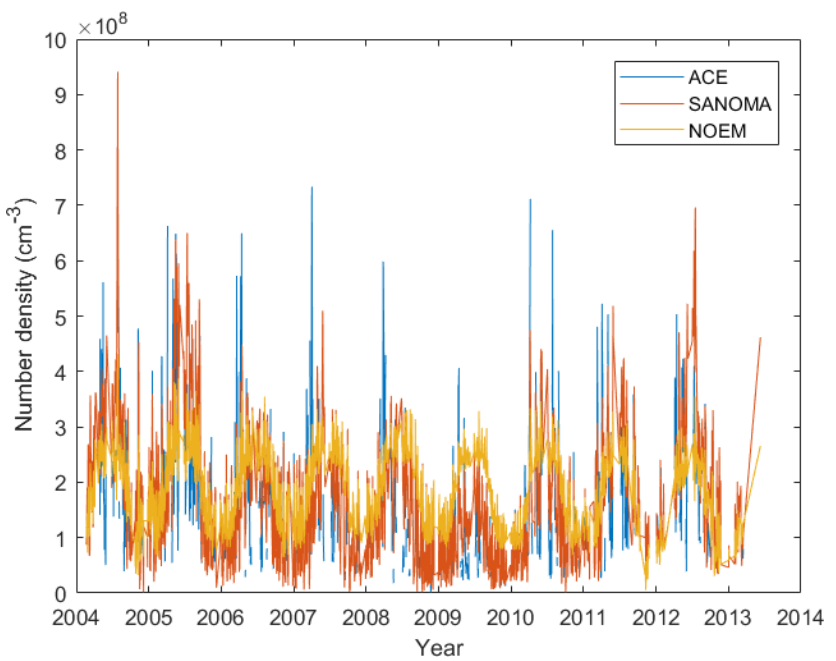

Figure 19. Time series of NO number density measured with ACE and simulated with SANOMA as well as NOEM, $102 \mathrm{~km}$ altitude, $-70^{\circ} \Lambda$.

ber density in ACE is located close to $100 \mathrm{~km}$, while the corresponding SANOMA and NOEM NO maxima are located between 102 and $108 \mathrm{~km}$.

The SANOMA $R^{2}$ values in Fig. 21a reach a maximum of 0.65 at $70^{\circ} \Lambda$ magnetic latitude while Fig. $21 \mathrm{~b}$ indicates that NOEM only attains 0.35 at $35^{\circ} \Lambda$ at $102 \mathrm{~km}$. Figure 21a also shows a band of lower $R^{2}$ from -45 to $-25^{\circ} \Lambda$, the cause of which remains unknown.

\subsection{MIPAS}

Finally, this section compares the simulated NO number densities with v5r 622 MIPAS (Bermejo-Pantaleon et al., 2011; Fischer et al., 2008) measured NO in the altitudes from 102 to $115 \mathrm{~km}$. In Fig. 22, although both NOEM and SANOMA seem to follow the variations of MIPAS-measured NO, SANOMA more accurately reproduces the number density of MIPAS. Especially during the period of low solar activity around 2009-2010 as indicated in Fig. 2, NOEM overestimates MIPAS NO, whereas SANOMA follows it more closely. Both models miss some highest spikes of NO, for instance during 2011. Figure 23a and b display the median differences between SANOMA and MIPAS as well as NOEM and MIPAS as a percentage of the MIPAS-measured NO. SANOMA ranges between $-40 \%$ at $115 \mathrm{~km}$ around $70^{\circ} \Lambda$ and $+100 \%$ at $102 \mathrm{~km}$ at $30^{\circ} \Lambda$ in comparison to MIPAS. The corresponding values for NOEM are $-20 \%$ at $80^{\circ} \Lambda$ and $+160 \%$ at $115 \mathrm{~km}$ and $50^{\circ} \Lambda$. Finally, Fig. $24 \mathrm{a}$ and $\mathrm{b}$ suggest that in both models, the $R^{2}$ varies with latitude. SANOMA explains up to $80 \%$ of the variance of MIPAS $\mathrm{NO}$ at the lower altitudes around $80^{\circ} \Lambda$, while NOEM only reaches $40 \%$ at $20^{\circ} \Lambda$.

\subsection{Summary of the results}

This section aims to summarize and elaborate on the results of the previous sections. To achieve an overview of the results, Table 3 presents $R^{2}$ values between the measurement instruments and three different models: (a) NOEM; (b) SMRNOEM, a model built using the NOEM equations, but Odin SMR data; and (c) SANOMA. Comparing NOEM and SMRNOEM informs us on any improvement provided by using the Odin SMR NO dataset instead of the SNOE dataset, while differences between SMRNOEM and SANOMA are results of the different approach to developing the two models.

Table 3 reveals that SANOMA consistently explains a similar amount, or more variance than SMRNOEM in all regions and for all instruments, which in turn explains more variance than the SNOE-based NOEM. With SOFIE, ACE, and SCIAMACHY, the median difference between SANOMA and these instruments is closer to zero than for NOEM.

Generally, the models capture more variance in the Northern than in the Southern Hemisphere. Perhaps the larger offset between the geomagnetic and geographic pole, or the more stable dynamics in the Southern Hemisphere affect the amount of NO in ways that are beyond the reach of these simple models.

The SMRNOEM values in Table 3 highlight how much the Odin SMR dataset itself improves the resulting empirical model and the consistently higher $R^{2}$ values in SANOMA 

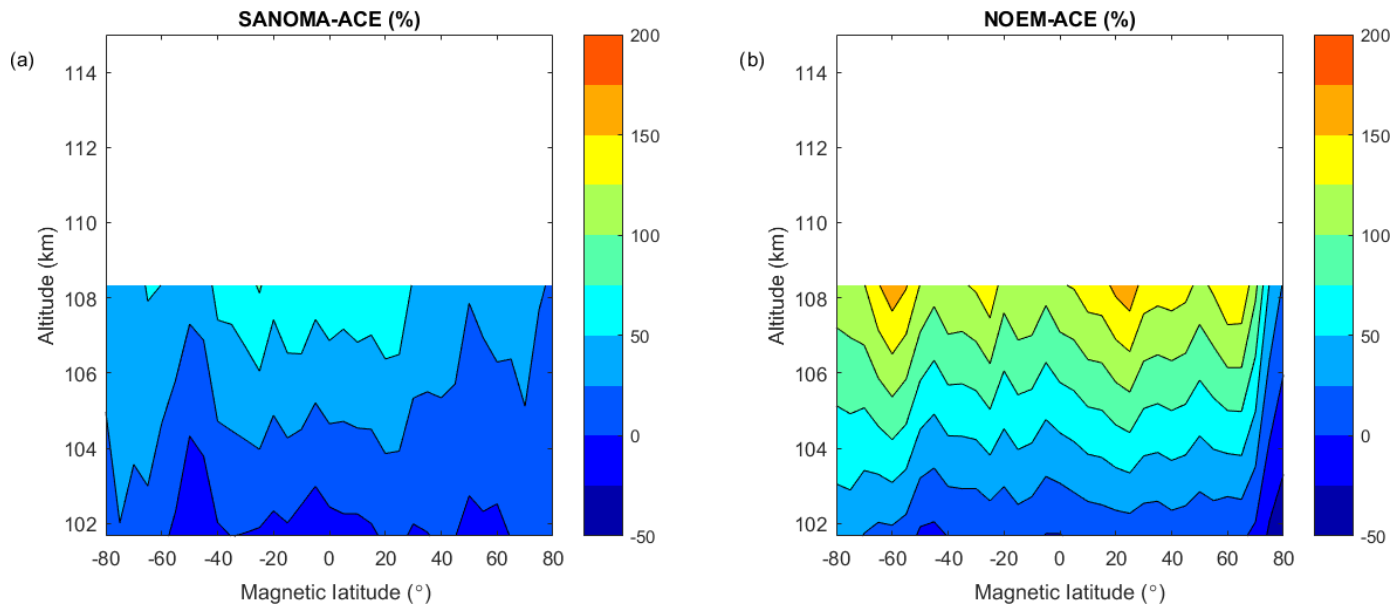

Figure 20. (a) Median difference between SANOMA and ACE as a percentage of mean ACE NO number density. (b) Median difference between NOEM and ACE as a percentage of mean ACE NO number density.
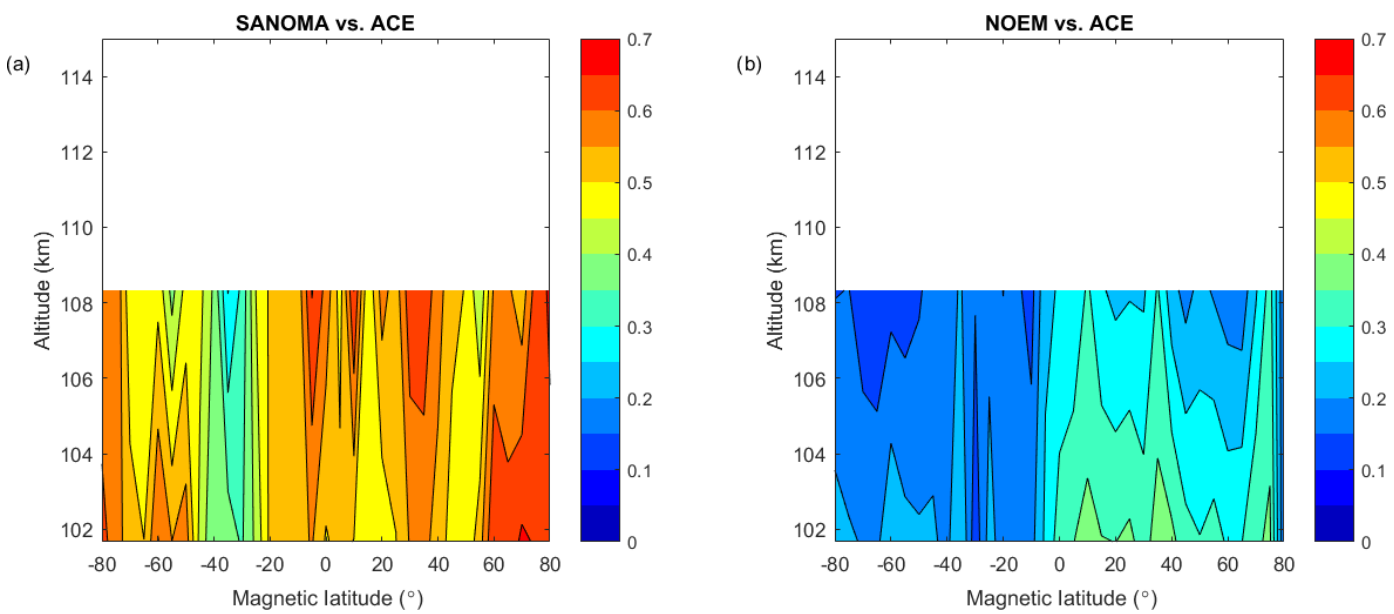

Figure 21. (a) Adjusted $R^{2}$ of a linear fit between SANOMA and ACE NO number density. (b) Adjusted $R^{2}$ of a linear fit between NOEM and ACE NO number density.

compared to SMRNOEM justify the use of the compound indices. Using the SANOMA equation instead of the NOEM equation with SMR-measured NO increased the percentage of explained variance by up to $100 \%$ near the magnetic poles. Moreover, these comparisons stem from $102 \mathrm{~km}$ and upwards, but as indicated by Fig. 11, SANOMA outperforms SMRNOEM by even more in the altitudes below $102 \mathrm{~km}$.

Since SMR measures both day- and nighttime NO, a positive difference compared to the daytime measuring instrument SCIAMACHY was expected. SANOMA is also characterized by a slight positive bias in comparison to the solar occultation instruments SOFIE and ACE-FTS, which could be due to differences in the diurnal sampling. The magnitude of the relative differences between SANOMA and each satellite is similar, although slightly higher than the differences between the SMR dataset and the other instruments described by Bender et al. (2015). As the time series in Figs. 13, 16,

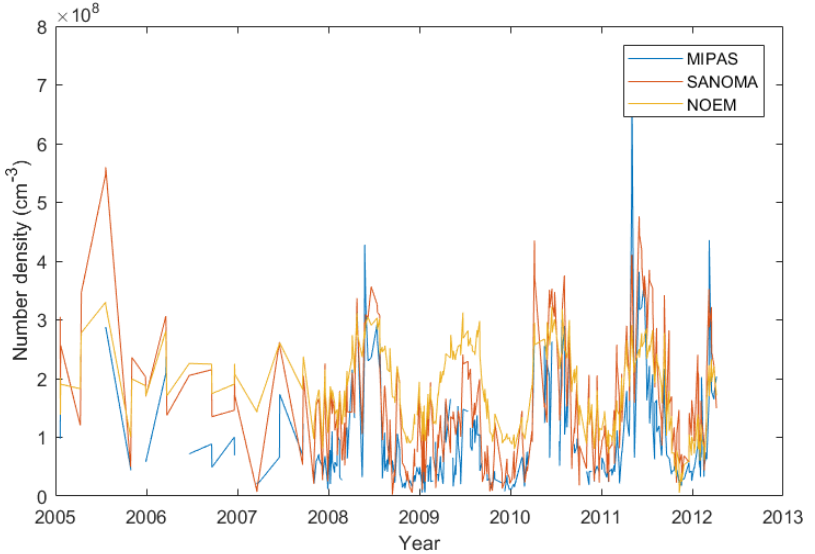

Figure 22. Time series of NO number density measured with MIPAS and simulated with SANOMA as well as NOEM, $102 \mathrm{~km}$ altitude, $-70^{\circ} \Lambda$. 

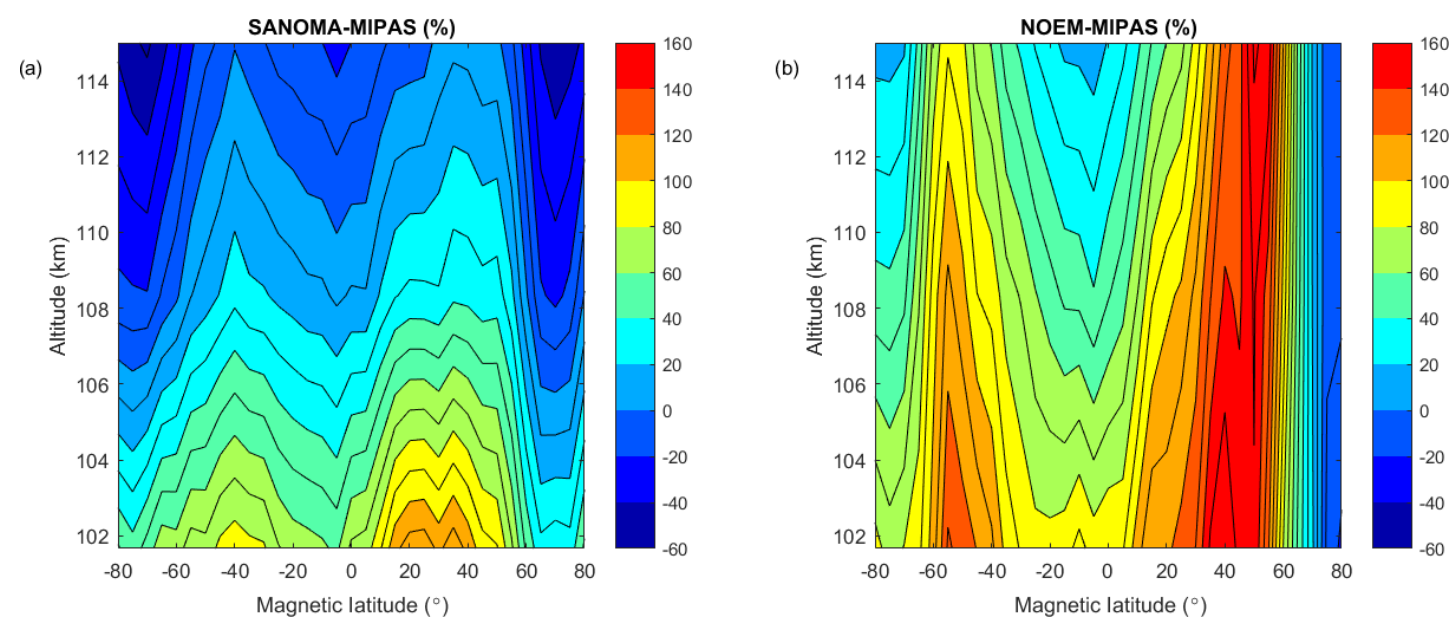

Figure 23. (a) Median difference between SANOMA and MIPAS as a percentage of mean MIPAS NO number density. (b) Median difference between NOEM and MIPAS as a percentage of mean MIPAS NO number density.
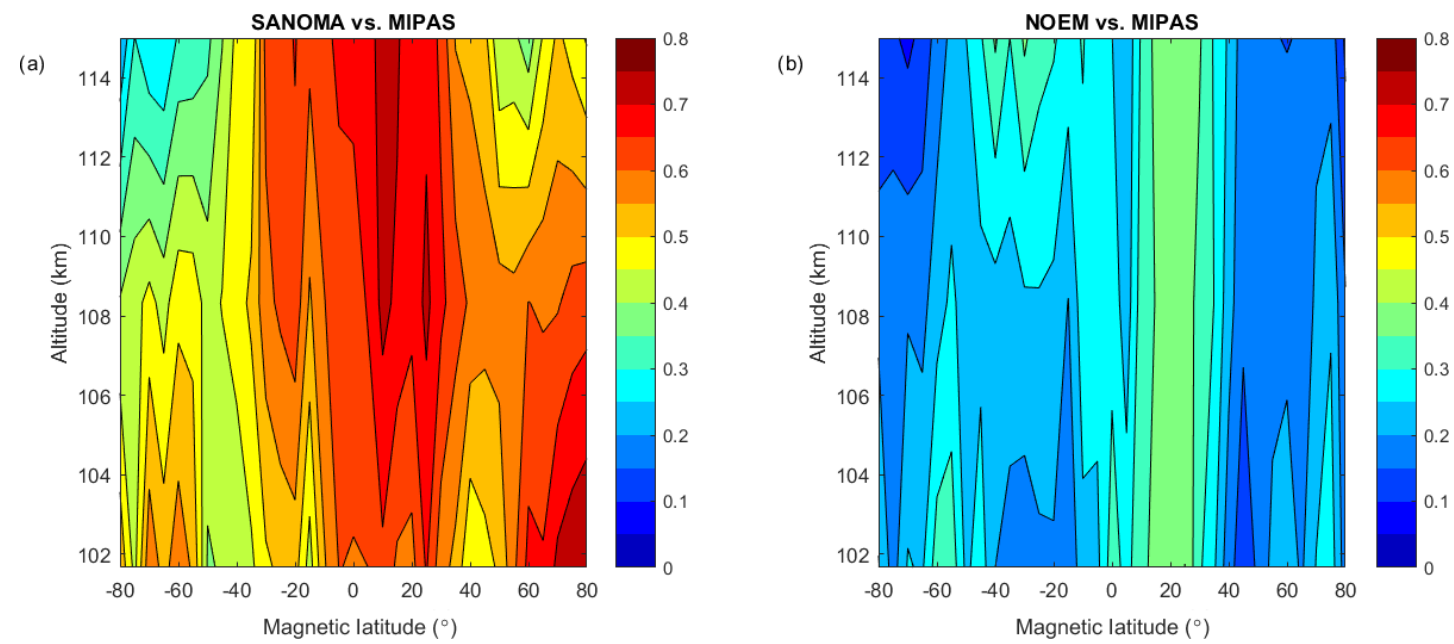

Figure 24. (a) Adjusted $R^{2}$ of a linear fit between SANOMA and MIPAS NO number density. (b) Adjusted $R^{2}$ of a linear fit between NOEM and MIPAS NO number density.

19 , and 22 showed, NOEM overestimates the measured NO prior to 2011. The fact that NOEM was derived from SNOE data between 1998 and 2000, a time of high solar activity, as indicated by Fig. 2, might explain why it fails to accurately reproduce the lower NO number densities observed at times of lower solar activity. SANOMA benefits from the wider variety of solar conditions experienced over the Odin SMR measurement period from 2004 to 2016 to provide more accurate NO number density over the entire solar cycle.

\section{Conclusion and discussion}

This study presented a new empirical model called SANOMA to simulate NO in the MLT. This model is based on V3.0 Odin SMR NO, to which we fit multivariate linear functions using the Kp index, solar declination, the log- arithm of the F10.7 cm flux, as well as two compound indices based on the Kp index and solar declination. These two compound indices attempt to account for the lifetime of NO in the absence of sunlight. SANOMA can capture an average of $63.9 \%$ of the variance of the Odin SMR NO between 88 and $116 \mathrm{~km}$ and between -80 and $80^{\circ} \Lambda$. The comparisons of SANOMA, the model developed in this study, and NOEM, a similar model by Marsh et al. (2004), with measurements from the SOFIE, SCIAMACHY, ACE, and MIPAS instruments suggest that SANOMA explains significantly more variance of the NO measured by each instrument than NOEM. The percentage of explained variance by SANOMA spans from a minimum of $16 \%$ in the magnetic tropics $\left(-30\right.$ to $\left.30^{\circ} \Lambda\right)$ with SCIAMACHY, to $73.2 \%$ in the magnetic tropics with SMR. Similarly, NOEM captures a minimum of $6.9 \%$ of the variance with SCIAMACHY NO in 
the magnetic tropics, and a maximum of $54.5 \%$ of the variance with SMR NO in the same region. Furthermore, the results show that SANOMA slightly overestimates the amount of NO. However, this overestimation is significantly lower than for NOEM, when compared with the measurements of the five instruments considered in this study.

An alternative to the multivariate linear fit in this study would have been EOF analysis such as in Marsh et al. (2004). We attempted this approach and compared the resulting model to SANOMA, with roughly equivalent success. The multivariate linear fit approach was then chosen for its simplicity.

Our original hypothesis that a model similar to NOEM, but derived using Odin SMR data, would result in a more accurate model was proven to be true. Comparing the results of NOEM and SANOMA with measured NO showed that, especially during times of low solar activity, NOEM overestimates NO by roughly $100 \%$. This could be attributed to the fact that NOEM was built on only 2 years of SNOE NO data from 1998 to 2000, a period of high solar activity. Hence, when the model is applied to low-activity periods, such as 2009-2010, the extrapolation from high-activity to low-activity conditions is inaccurate, resulting in large errors of NOEM NO compared to the measurements.

In terms of explaining the variation of NO, unlike NOEM, SANOMA manages to recreate more of the highest concentrations of NO. SANOMA still fails to explain some of the highest spikes of NO and suffers from a relatively coarse $(6.5 \mathrm{~km})$ altitude resolution as well as a narrow altitude range $(85-115 \mathrm{~km})$. The results from Fig. 12 suggested that SANOMA fails to model some physical processes that govern the amount of NO. Perhaps dynamical processes cause fluctuations in the concentration of $\mathrm{NO}$ at $85 \mathrm{~km}$, causing the model to miss some of the variation of NO. However, the error associated with SANOMA has been estimated and is available to any potential user of the model.

Creating SANOMA with all SMR measurements will have likely introduced a positive bias compared to day-measuring instruments, such as SCIAMACHY, since nighttime NO is expected to be higher than daytime NO. An alternative to the current model would be to provide two versions of SANOMA: one for day, and one for night.

Although no rigorous validation of Odin SMR NO in the MLT regions exists, Bender et al. (2015) proposed that the Odin SMR is consistent with measurements from other satellites. However, it is conceivable that all of these measurements could deviate from the true concentration of NO. Even so, SANOMA offers an estimate that reflects the physical processes behind the creation of NO. As long as no in situ measurements are available, remote sensing is the only way to provide some estimate of the true state. SANOMA could be used in the future as an input for chemical models of the atmosphere, as a priori information for satellite retrievals of $\mathrm{NO}$, or as a transfer function to compare NO observational datasets with each other, to name a few possible applica- tions. SANOMA and accompanying scripts are available on http://odin.rss.chalmers.se (last access: 15 September 2018).

Data availability. The observation dataset used to develop SANOMA is available to any potential user on http://odin.rss.chalmers.se/level2 (Odin SMR, 2018), under the project name "development/ALL", for the frequency mode 21. Instructions on how to use the SANOMA model, as well as the associated coefficients, have been made available on the home page of the Odin website (http://odin.rss.chalmers.se, SANOMA, 2018).

Author contributions. JK wrote the main body of text, carried out the work behind SANOMA, analyzed satellite and index data, and created all plots. KP initiated the study and took part in scientific consulting, editing of the text, and input on correctness of facts, among other contributions. Both DM and PE took part in scientific consulting and editing of the text.

Competing interests. The authors declare that they have no conflict of interest.

Acknowledgements. Odin is a Swedish-lead satellite project funded jointly by Sweden (SNSB), Canada (CSA), Finland (TEKES), France (CNES), and the Third-Party Missions programme of the European Space Agency (ESA). The following people have kindly provided their support by the method indicated in the brackets: Koen Hendrickx (providing SOFIE data), Daniel Marsh (providing NOEM and general feedback), Kaley Walker (providing ACE data), Stefan Bender (providing SCIAMACHY data), and Jean Lilensten (providing general feedback on the model). We would also like to thank the two reviewers for their helpful comments.

Edited by: William Ward

Reviewed by: Bernd Funke and one anonymous referee

\section{References}

Baker, D., Barth, C., Mankoff, K., Kanekal, S., Bailey, S., Mason, G., and Mazur, J.: Relationships between precipitating auroral zone electrons and lower thermospheric nitric oxide densities: 1998-2000, J. Geophys. Res.-Space, 106, 24465-24480, 2001.

Barth, C., Mankoff, K., Bailey, S., and Solomon, S.: Global observations of nitric oxide in the thermosphere, J. Geophys. Res.-Space, 108, 1027, https://doi.org/10.1029/2002JA009458, 2003.

Barth, C. A., Bailey, S. M., and Solomon, S. C.: Solar-terrestrial coupling: Solar soft x-rays and thermospheric nitric oxide, Geophys. Res. Lett., 26, 1251-1254, 1999.

Bender, S., Sinnhuber, M., Burrows, J. P., Langowski, M., Funke, B., and López-Puertas, M.: Retrieval of nitric oxide in the mesosphere and lower thermosphere from SCIAMACHY limb spectra, Atmos. Meas. Tech., 6, 2521-2531, https://doi.org/10.5194/amt-6-2521-2013, 2013. 
Bender, S., Sinnhuber, M., von Clarmann, T., Stiller, G., Funke, B., López-Puertas, M., Urban, J., Pérot, K., Walker, K. A., and Burrows, J. P.: Comparison of nitric oxide measurements in the mesosphere and lower thermosphere from ACE-FTS, MIPAS, SCIAMACHY, and SMR, Atmos. Meas. Tech., 8, 4171-4195, https://doi.org/10.5194/amt-8-4171-2015, 2015.

Bermejo-Pantaleon, D., Funke, B., Lopez-Puertas, M., GarciaComas, M., Stiller, G. P., von Clarmann, T., Linden, A., Grabowski, U., Hoepfner, M., Kiefer, M., Glatthor, N., Kellmann, S., and Lu, G.: Global observations of thermospheric temperature and nitric oxide from MIPAS spectra at $5.3 \mu \mathrm{m}$, J. Geophys. Res.-Space, 116, A10313, https://doi.org/10.1029/2011JA016752, 2011.

Bernath, P. F., McElroy, C. T., Abrams, M., Boone, C. D., Butler, M., Camy-Peyret, C., Carleer, M., Clerbaux, C., Coheur, P.-F., Colin, R., DeCola P., DeMaziére, M., Drummond, J. R., Dufour, D., Evans, W. F. J., Fast, H., Fussen, D., Gilbert, K., Jennings, D. E., Llewellyn, E. J., Lowe, R. P., Mahieu, E., McConnel, J. C., McHugh, M., McLeod, S. D., Michaud, R., Midwinter, C., Nassar, R., Nichitiu, F., Nowlan, C., Rinsland, C. P., Rochon, Y. J., Rowlands, N., Semeniuk, K., Simon, P., Skelton, R., Sloan, J. J., Soucy, M.-A., Strong, K., Tremblay, P., Turnbull, D., Walker, K. A., Walkty, I., Wardle, D. A., Wehrle, V., Zander, R., and Zou, J.: Atmospheric chemistry experiment (ACE): mission overview, Geophys. Res. Lett., 32, L15S01, https://doi.org/10.1029/2005GL022386, 2005.

Fischer, H., Birk, M., Blom, C., Carli, B., Carlotti, M., von Clarmann, T., Delbouille, L., Dudhia, A., Ehhalt, D., Endemann, M., Flaud, J. M., Gessner, R., Kleinert, A., Koopman, R., Langen, J., López-Puertas, M., Mosner, P., Nett, H., Oelhaf, H., Perron, G., Remedios, J., Ridolfi, M., Stiller, G., and Zander, R.: MIPAS: an instrument for atmospheric and climate research, Atmos. Chem. Phys., 8, 2151-2188, https://doi.org/10.5194/acp-8-21512008, 2008.

Frisk, U., Hagstrom, M., Ala-Laurinaho, J., Andersson, S., Berges, J., Chabaud, J., Dahlgren, M., Emrich, A., Floren, G., Florin, G., Fredrixon, M., Gaier, T., Haas, R., Hirvonen, T., Hjalmarsson, A., Jakobsson, B., Jukkala, P., Kildal, P., Kollberg, E., Lassing, J., Lecacheux, A., Lehikoinen, P., Lehto, A., Mallat, J., Marty, C., Michet, D., Narbonne, J., Nexon, M., Olberg, M., Olofsson, A., Olofsson, G., Origne, A., Petersson, M., Piirone, P., Pouliquen, D., Ristorcelli, I., Rosolen, C., Rouaix, G., Raisanen, A., Serra, G., Sjoberg, F., Stenmark, L., Torchinsky, S., Tuovinen, J., Ullberg, C., Vinterhav, E., Wadefalk, N., Zirath, H., Zimmermann, P., and Zimmermann, R.: The Odin satellite - I. Radiometer design and test, Astron. Astrophys., 402, L27-L34, https://doi.org/10.1051/0004-6361:20030335, 2003.

Fuller-Rowell, T.: Modeling the solar cycle change in nitric oxide in the thermosphere and upper mesosphere, J. Geophys. Res.Space, 98, 1559-1570, 1993.

Gérard, J.-C. and Barth, C.: High-latitude nitric oxide in the lower thermosphere, J. Geophys. Res., 82, 674-680, 1977.

Gordley, L. L., Hervig, M. E., Fish, C., Russell, J. M., Bailey, S., Cook, J., Hansen, S., Shumway, A., Paxton, G., Deaver, L., Marshall, T., Burton, J., Magill, B., Brown, C., Thompson, E., and Kemp, J.: The solar occultation for ice experiment, J. Atmos. Sol.-Terr. Phy., 71, 300-315, 2009.

Hendrickx, K., Megner, L., Gumbel, J., Siskind, D. E., Orsolini, Y. J., Tyssoy, H. N., and Hervig, M.: Observation of 27 day solar cycles in the production and mesospheric descent of EPP-produced NO, J. Geophys. Res.-Space, 120, 8978-8988, https://doi.org/10.1002/2015JA021441, 2015.

Ljung, G. M. and Box, G. E.: On a measure of lack of fit in time series models, Biometrika, 65, 297-303, https://doi.org/10.1093/biomet/65.2.297, 1978.

Marsh, D., Solomon, S., and Reynolds, A.: Empirical model of nitric oxide in the lower thermosphere, J. Geophys. Res.-Space, 109, A07301, https://doi.org/10.1029/2003JA010199, 2004.

Menvielle, M. and Berthelier, A.: The K-derived planetary indexes - description and availability, Rev. Geophys., 29, 415-432, https://doi.org/10.1029/91RG00994, 1991.

Menvielle, M., Iyemori, T., Marchaudon, A., and Nosé, M.: Geomagnetic indices, in: Geomagnetic Observations and Models, 183-228, Springer, Netherlands, 2011.

Minschwaner, K. and Siskind, D.: A New Calculation of NitrixOxide Photolysis in the Stratosphere, Mesosphere, and Lower Thermosphere, J. Geophys. Res.-Atmos., 98, 20401-20412, https://doi.org/10.1029/93JD02007, 1993.

Murtagh, D., Frisk, U., Merino, F., Ridal, M., Jonsson, A., Stegman, J., Witt, G., Eriksson, P., Jimenez, C., Megie, G., de la Noe, J., Ricaud, P., Baron, P., Pardo, J., Hauchcorne, A., Llewellyn, E., Degenstein, D., Gattinger, R., Lloyd, N., Evans, W., McDade, I., Haley, C., Sioris, C., von Savigny, C., Solheim, B., McConnell, J., Strong, K., Richardson, E., Leppelmeier, G., Kyrola, E., Auvinen, H., and Oikarinen, L.: An overview of the Odin atmospheric mission, Can. J. Phys., 80, 309-319, https://doi.org/10.1139/P01157, 2002.

Odin SMR: development/ALL, frequency mode 21, available at: http://odin.rss.chalmers.se/level2, last access: 15 September 2018.

Pérot, K., Urban, J., and Murtagh, D. P.: Unusually strong nitric oxide descent in the Arctic middle atmosphere in early 2013 as observed by Odin/SMR, Atmos. Chem. Phys., 14, 8009-8015, https://doi.org/10.5194/acp-14-8009-2014, 2014

Richards, P., Torr, M., and Torr, D.: The seasonal effect of nitric-oxide cooling on the thermospheric UV heat-budget, Planet. Space Sci., 30, 515-518, https://doi.org/10.1016/00320633(82)90062-9, 1982.

SANOMA: Model instructions, available at: http://odin.rss. chalmers.se, last access: 15 September 2018.

Sheese, P. E., Strong, K., Gattinger, R. L., Llewellyn, E. J., Urban, J., Boone, C. D., and Smith, A. K.: Odin observations of Antarctic nighttime NO densities in the mesosphere-lower thermosphere and observations of a lower NO layer, J. Geophys. Res.Atmos., 118, 7414-7425, https://doi.org/10.1002/jgrd.50563, 2013.

Sinnhuber, M., Nieder, H., and Wieters, N.: Energetic particle precipitation and the chemistry of the mesosphere/lower thermosphere, Surv. Geophys., 33, 1281-1334, 2012.

Siskind, D., Nedoluha, G., Randall, C., Fromm, M., and Russell, J.: An assessment of Southern Hemisphere stratospheric $\mathrm{NO}_{x}$ enhancements due to transport from the upper atmosphere, Geophys. Res. Lett., 27, 329-332, https://doi.org/10.1029/1999GL010940, 2000.

Solomon, S. C., Barth, C. A., and Bailey, S. M.: Auroral production of nitric oxide measured by the SNOE satellite, Geophys. Res. Lett., 26, 1259-1262, 1999. 
Tapping, K. and Detracey, B.: The origin of the $10.7 \mathrm{~cm}$ flux, Sol. Phys., 127, 321-332, https://doi.org/10.1007/BF00152171, 1990.

Thebault, E., Finlay, C. C., Beggan, C. D., Alken, P., Aubert, J., Barrois, O., Bertrand, F., Bondar, T., Boness, A., Brocco, L., Canet, E., Chambodut, A., Chulliat, A., Coisson, P., Civet, F., Du, A., Fournier, A., Fratter, I., Gillet, N., Hamilton, B., Hamoudi, M., Hulot, G., Jager, T., Korte, M., Kuang, W., Lalanne, X., Langlais, B., Leger, J.-M., Lesur, V., Lowes, F. J., Macmillan, S., Mandea, M., Manoj, C., Maus, S., Olsen, N., Petrov, V., Ridley, V., Rother, M., Sabaka, T. J., Saturnino, D., Schachtschneider, R., Sirol, O., Tangborn, A., Thomson, A., Toffner-Clausen, L., Vigneron, P., Wardinski, I., and Zvereva, T.: International Geomagnetic Reference Field: the 12th generation, Earth Planet. Space, 67, 79, https://doi.org/10.1186/s40623-015-0228-9, 2015.
Wallace, J. M. and Hobbs, P. V.: Atmospheric science: an introductory survey, Vol. 92, Academic press, USA, 2006. 